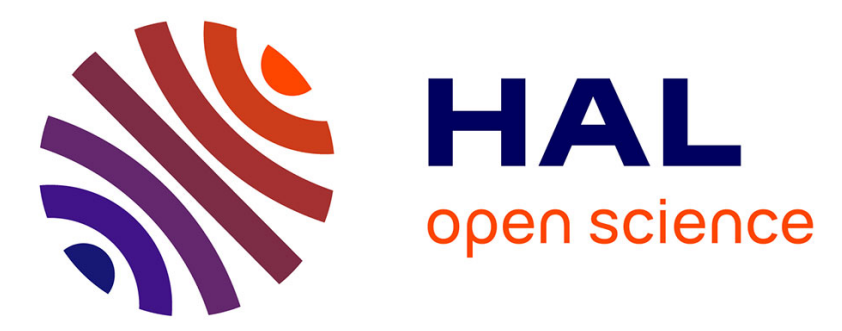

\title{
Why housing and transport costs should always be considered together: A monocentric analysis of prudential measures in housing access
}

Nicolas Coulombel

\section{- To cite this version:}

Nicolas Coulombel. Why housing and transport costs should always be considered together: A monocentric analysis of prudential measures in housing access. Transport Policy, 2018, 65, pp.89-105. 10.1016/j.tranpol.2017.04.011 . hal-01712822

\section{HAL Id: hal-01712822 \\ https://hal.science/hal-01712822}

Submitted on 4 Dec 2019

HAL is a multi-disciplinary open access archive for the deposit and dissemination of scientific research documents, whether they are published or not. The documents may come from teaching and research institutions in France or abroad, or from public or private research centers.
L'archive ouverte pluridisciplinaire HAL, est destinée au dépôt et à la diffusion de documents scientifiques de niveau recherche, publiés ou non, émanant des établissements d'enseignement et de recherche français ou étrangers, des laboratoires publics ou privés. 


\title{
Why housing and transport costs should always be considered together: a monocentric analysis of prudential measures in housing access
}

\author{
Nicolas Coulombel ${ }^{a, *}$ \\ a Université Paris-Est, Laboratoire Ville Mobilité Transport, Bâtiment Bienvenue \\ 6 et 8 avenue Blaise Pascal, 77455 Marne-la-Vallée cedex 2, France
}

\begin{abstract}
This paper compares the effects of two prudential measures in housing access on the solvency and welfare of households, with specific attention to transport costs as well as equity issues. A widespread regulation is to cap the housing expense ratio (defined as the share of income spent on the rent or the monthly loan installment), typically at one third of income or so. Using the canonical model of urban economics, the monocentric model, we show that capping the housing expense ratio drives low-income households to move away from the city center toward suburban areas, where they face high transport costs. This unintended eviction effect lowers the efficiency of this prudential measure as far as household solvency is concerned. Capping the overall housing plus transport expense ratio precludes this eviction mechanism and unequivocally proves more efficient in protecting household solvency, including from strong variations in transport prices such as during fuel price spikes. Additionally, by limiting the bidding capacity of households, both prudential measures lead to a decrease in housing prices. This tends to improve the welfare of households, firstly of high-income ones (as they are less affected by the constraints). The effect on housing prices is stronger when capping the housing expense ratio, so that households, again firstly high-income ones, are typically better off (in terms of welfare) than when one caps the housing plus transport expense ratio, however. Considering the primary objective of prudential measures - protecting the solvency of households, firstly of low-income ones - our findings call for the inclusion of transport costs within prudential ratios, as well as indicators of housing affordability. This would incidentally raise public awareness with regard to the high costs of private cars, which are often underestimated. A short numerical application to the Paris region corroborates that a policy change from housing prudential ratios toward comprehensive housing plus transport prudential ratios might significantly improve the situation of low-income households.
\end{abstract}

Keywords: housing, transport, budget constraints, monocentric model.

\footnotetext{
*Corresponding Author: E-mail: nicolas.coulombel@enpc.fr. Tel: (+33) 181668880
} 


\section{Introduction}

For homebuyer and private renter households, housing typically represents the primary cost item. In France, private tenants spent on average $19.3 \%$ of their income on housing in 2006, and recent homebuyers $22.8 \%$ (CGDD and SOeS, 2009). In the US, these figures reached $29 \%$ and $43 \%$ respectively for year 2010 in the case of moderate-income households (Hickey et al., 2012). ${ }^{1}$ Accordingly, lenders apply several prudential measures when considering mortgage applications to limit the risk of default. One of the standard underwriting guidelines is that the monthly installment should not exceed a given fraction of the homebuyer household income, typically one third or so. Likewise, in the private rental sector landlords often require from prospective tenants to earn at least three to four times the rent, again to ensure that the tenant has the financial capacity to sustain this rent level over the long term.

These prudential measures, though relatively sound at first glance, are actually quite controversial. In tight housing markets, they would encourage households, especially low-income ones, to move away from the (expensive) urban center and to settle in more distant neighborhoods so that they can afford their housing wishes (homeownership, a bigger home ...). Suburban and rural lifestyles involve high transportation costs, however. These transportation costs, often misestimated by households, would lead to a heavy housing plus transport bill and would ultimately increase the risk of insolvency, as argued by Hare (1994) in the case of the US or by Polacchini and Orfeuil (1999) regarding France. ${ }^{2}$ Furthermore, the heavy transport costs of remote households make them especially vulnerable to fuel price spikes. In France, Montagnon and Ringenbach (2013) estimate that the share of households spending more than $60 \%$ of their income on housing and transport costs would rise from $3 \%$ to $60 \%$ were fuel prices to double. To avoid these unintended consequences, several researchers advocate the inclusion of transportation costs within prudential indicators (Hare, 1994; Holtzclaw et al., 2002; Polacchini and Orfeuil, 1999). Yet the relevance of their proposition remains controversial to this day. Empirical evidence on the issue remains mixed, and is limited by the unavailability of adequate data (Kaza et al., 2016), while theoretical works are seldom, if any (Chatman and Voorhoeve, 2010).

This paper intends to shed light on this issue by studying the effects of the two prudential measures - capping either the housing budget or the joint housing plus transportation budget at a given fraction of the household's income - from a theoretical perspective. Two questions are of particular interest: 1) do these regulations improve the solvency of households indeed, in particular of low-income ones, as they are intended to and 2) how do they affect the household welfare. We use the canonical model of urban economics, the monocentric model. This allows us to capture spatial and equilibrium effects.

\footnotetext{
${ }^{1}$ Moderate-income households are defined as households earning between 50 and $100 \%$ of the median income.

${ }^{2}$ Instances of households who misestimated the cost of remoteness are plethora and often relayed by the press (e.g. http://rue89.nouvelobs.com/2014/02/16/lerreur-petite-maison-village-640-euros-gasoil-mois-249978).
} 
Indeed, because housing prices and transport costs strongly vary within a metropolitan area, setting constraints on the housing and/or transport budgets is likely to modify households' location choices. Similarly, as both prudential measures limit the households' bidding capacity, they are likely to cause a decrease in housing prices through equilibrium mechanisms, and thereby influence the solvency and utility of households. Acknowledging income as a key determinant of housing and transport budgets (Coulombel and Leurent, 2013; Haas et al., 2006), two household classes are considered in the model: low-income and high-income. The analysis focuses on the situation of low-income households, however, as the ones who face the highest housing plus transportation burdens and are therefore the most subject to solvency issues (Renne and Sturtevant, 2016).

Our results corroborate the claims regarding the unintended effects of housing budget constraints. Capping only the housing expense compels low-income households to move away from the city center, at the cost of high transport budgets. If the constraint is too stringent, low-income households are completely evicted from the central parts of the city, entailing a strong deterioration of their solvency. Capping the sum of housing and transport expenses precludes this eviction mechanism and ultimately proves more efficient in protecting the solvency of low-income households. Regarding welfare effects, both measures limit the households' bidding capacity and thereby involve a decrease in housing prices. This tends to improve the welfare of households, firstly of high-income ones (who are less affected by the constraints). The effect on housing prices is stronger for the housing constraint, so that households, again firstly high-income ones, are typically better off than under the housing plus transport constraint. Considering the primary objective of prudential measures - protecting the solvency of households, firstly of low-income ones - our findings call for the inclusion of transport costs within prudential ratios, as well as indicators of housing affordability. This would incidentally raise $c$

The layout of the paper is as follows. Section 2 reviews the literature. Section 3 presents the monocentric model, and Section 4 preliminary results in the unconstrained case. Sections 5 and 6 investigate the effects of capping either the housing budget or the joint housing plus transport budget, respectively. Section 7 further explores the influence of transport costs. Section 8 carries out a short application to the Paris region. Last, Section 9 discusses the main findings and provides policy recommendations by way of conclusion. All proofs are sent back to the Appendix.

\section{Literature review}

When considering household solvency through the prism of housing affordability as we do here, two indicators prevail in the literature: the housing expense ratio and the residual income (Revington and Townsend, 2016). We discuss the two indicators and their relationship to prudential measures. 
The housing expense ratio (also referred to as the housing burden, and as the front-end ratio in the underwriting lexicon) measures the share of income spent on housing. Typically, housing is considered unaffordable if the household allows more than $30 \%$ of its income to housing expenses (Stone, 2006). ${ }^{3}$ This simple rule-of-thumb is actually also often used as a standard prudential rule in the rental and owner-occupied markets. In the US, the threshold of $30 \%$ currently remains the standard in most rental housing programs (Schwarz and Wilson, 2008). Similarly, most current underwriting guidelines include a PITI (principal, interest, tax and insurance payment) threshold hovering around $30 \%$. In France, landlords typically require from prospective tenants to earn at least three times the rent, while most lenders also use the 33\% PITI threshold as conventional underwriting guidelines (Coulombel, 2016). The expense ratio indicator is straightforward to compute and easily available, which explains its wide use be it in the academic literature or in practice as a prudential measure. As a matter of fact, it is also used in other fields to study (domestic) fuel poverty or transport vulnerability (Berry et al., 2016). Furthermore, there is now large empirical evidence that excessive front-end ratios strongly increase the risk of mortgage delinquency, supporting the current underwriting guidelines (Kaza et al., 2016). On the other hand, ratio-type indicators are often criticized on the grounds that a same value of the ratio may reflect very contrasted situations depending on the household income level. For instance, households are less likely to be able to sustain a housing burden of $30 \%$ if they are near the poverty line than if they are well above the median-income level.

In view of the limitations of ratio-type indicators, the residual income approach considers the income left after subtracting expenses relative to one or several budget items (e.g. housing), and seeks to evaluate whether this residual income is sufficient to meet the household's (remaining) basic needs. While first works only subtracted housing costs (Kutty, 2005; Stone, 2006), there is growing consensus that both housing and transportation costs should be included in measures of housing affordability (Fisher et al., 2009; Hickey et al., 2012; Renne and Sturtevant, 2016). Like a same value of the housing burden may correspond to very contrasted situations depending on the income level, this holds true of the location of the household and of the transportation expenses that it faces. As a matter of fact, transport costs strongly vary within metropolitan areas, typically rising with distance to the city center (or to the nearest employment center for polycentric cities). For instance, in Philadelphia the mean transport expense ratio of a moderate-income household remained in 2010 below $20 \%$ close to the city center, but exceeded $30 \%$ in the most remote parts of the metropolitan area (Hickey et al., 2012).

\footnotetext{
${ }^{3}$ While the precise scope of housing costs may vary, it typically includes: rents (for tenants) or loan payments (for home buyers), insurance, and taxes. Utilities and home maintenance are also sometimes included.
} 
As housing burdens vary considerably less than transport burdens within most metropolitan areas, several works report that the joint housing plus transport burden strongly increases with distance to the city center (Berri, 2007; Coulombel et al., 2007; Hickey et al., 2012; Polacchini and Orfeuil, 1999). ${ }^{4}$ To illustrate, in the Paris region the median-income household allocated on average $50 \%$ of its income on housing and transport in rural areas in 2001, against only 32\% in inner Paris (Coulombel et al., 2007). Arguing that high housing plus transport burdens are likely to increase the risk of insolvency, the same works advocate including transport costs within prudential ratios. ${ }^{5}$

In the remainder of the text, we refer to the first category of prudential measures limiting only the housing burden as $\mathrm{CH}$ policies (for Capped Housing expense ratio), and to the second limiting the housing plus transport burden as CHT policies (for Capped Housing plus Transport expense ratio).

Whether $\mathrm{CHT}$ policies are truly preferable over $\mathrm{CH}$ policies actually remains a controversial issue, in particular due to the paucity of scholarly works (Chatman and Voorhoeve, 2010). A first strand of the literature examines the hypothesis underlying $\mathrm{CHT}$ policies that excessive transportation costs like excessive housing costs - increase the risk of mortgage delinquency. Although recent works do corroborate this point to a smaller or greater extent (Kaza et al., 2016; Pivo, 2014; Rauterkus et al., 2010), empirical evidence remains somewhat inconclusive and a few works actually find no influence of location accessibility on the risk of default (e.g. Blackman and Krupnick, 2001). Furthermore, all works are limited by the unavailability of the household's transportation budget in home loan datasets, so that some accessibility measure (e.g. walk score, gravity index, number of vehicles) must be used as a proxy instead. Another strand of the literature investigates the effects of borrowing constraints including the $\mathrm{CH}$ but also the down payment constraint - on tenure choice and housing demand. However, these works do not consider location choices as well as effects on housing supply and prices. ${ }^{6}$ Similarly, transport costs are seldom considered.

This work extends the existing literature by investigating the effects of $\mathrm{CH}$ and $\mathrm{CHT}$ policies using the monocentric model. This allows us to consider the effects on households' location choices as well as on real estate prices, two points rarely addressed in the literature. To the best of our knowledge, this paper is also the first to compare the impact of $\mathrm{CH}$ and $\mathrm{CHT}$ policies in a systematic manner and within a same analytical framework.

\footnotetext{
${ }^{4}$ See also Nicolas et al. (2012) regarding the spatial trends of transport costs within metro areas in France.

${ }^{5} \mathrm{C}$ urrent underwriting guidelines already consider transport costs to some (minor) extent, as car loans payments are included in the overall debt-to-income ratio. However, the threshold for the debt-to-income ratio is typically higher than for the front-end ratio, and loan payments are but a part of the auto full cost. In the rental market, landlords seldom if at all consider transport costs to screen tenants.

${ }^{6}$ See Gobillon (2008) for a survey of the literature on this topic.
} 


\section{The monocentric model}

The monocentric model was first formulated by Alonso (1964), who adapted the seminal work of Von Thünen (1826) to an urban context. This model aims to analyze households' location choices and housing price formation within a metropolitan area, while putting primary emphasis on households' trade-offs between housing and transportation costs. Frequently used to study the effects of land-use regulations such as floor area ratios or urban growth boundaries (Bertaud and Brueckner, 2005; Brueckner, 2009; Turner et al., 2014), the monocentric model is especially suited to the analysis of $\mathrm{CH}$ and CHT policies, which bear on the very housing and transport costs that are at the core of the model. After shortly reviewing the monocentric model, ${ }^{7}$ this section presents the solvency indicators and the model specification that are used for our study.

\subsection{Basic principles}

In the standard monocentric model, all jobs are assumed to be located in a single point referred to as the Central Business District (CBD). ${ }^{8}$ Each household commutes to the CBD on a daily basis for work, and earns an income $Y$. The commuting cost, noted $T(r)$, strictly increases with distance $r$ to the CBD. ${ }^{9}$ There are three goods in the economy: transport, land, and a composite good. The composite good stands for all other goods in the economy besides transportation and land; it is taken as the numéraire. To keep the model tractable, it is assumed households do not derive utility from travel. Accordingly, the household utility maximization problem writes:

$$
\max _{z, s, r} U(z, s) \text { s.t. } R(r) s+z+T(r)=Y \text {, }
$$

where $z$ and $s$ are the quantities of composite good and of land consumed, respectively, and $R(r)$ is the unit land rent at distance $r$ from the CBD. When choosing its location $r$, the household faces a trade-off between accessibility (as measured by transport costs $T(r)$ ) and housing prices (i.e. $R(r)$ ). The gist of the monocentric model is that housing prices are set endogenously through a bid auction mechanism, and reflect at equilibrium the comparative advantage of a location in terms of accessibility. Travel cost savings associated to proximity to the CBD are therefore capitalized in land rents.

Land supply is represented by a function $L(r)$ which measures the quantity of land available at distance $r$ from the CBD. Landlords can rent to either the agricultural sector or the residential sector (households), who compete for land. Landlords are profit-maximizers, and rent to the highest bidder.

\footnotetext{
7 See Fujita (1989) for a thoroughgoing presentation and analysis of the monocentric model.

${ }^{8}$ Several works lift this assumption (Brueckner, 1979; Legras, 2015; Ogawa and Fujita, 1980; White, 1988; Yinger, 1992), but at the cost of great analytical complexity. See Breteau and Leurent (2010) for a review.

${ }^{9}$ Space is assumed isotropic around the CBD, so that only the distance $r$ to the CBD matters.
} 
The agricultural sector is represented by a constant positive bid rent function $R_{A} \geq 0$, whereas the household bid-rent function is noted $\Psi(r, u)$, with:

$$
\Psi(r, u)=\max _{z, s}\left\{\frac{Y-T(r)-z}{S} \mid U(z, s)=u\right\} .
$$

$\Psi(r, u)$ is the maximum bid price (per surface unit) that a household can offer at location $r$ and still achieve the utility level $u$. Landlords rent to the highest bidder, hence:

$$
R(r)=\max \left(\Psi(r, u), R_{A}\right)
$$

Last, we consider the standard case of a closed-city with fixed population $N$ and absentee landlords (meaning land rents exit the economy). At equilibrium, all households have the same utility level $u_{e}$, hence the following conditions regarding $u_{e}$ and city size $r_{f}$ :

$$
\begin{gathered}
\Psi\left(r_{f}, u_{e}\right)=R_{A}, \\
\int_{0}^{r_{f}} n(r) d r=N,
\end{gathered}
$$

where $n(r)=L(r) / s\left(r, u_{e}\right)$ is the equilibrium population density at location $r$. The first condition (4) states that at the city border $r_{f}$, the household bid rent function is equal to the agricultural land rent. The second condition (5) is the population constraint: integrating density within the city boundaries yields the total population $N$ (i.e. all households must be accommodated).

\subsection{Indicators of household solvency}

In the ensuing sections, we will consider three main indicators to describe the household financial situation: the housing expense ratio, the housing plus transport expense ratio, and the solvency level. In the monocentric model, the housing expense ratio is given by $\tau_{H}(r)=R(r) s / Y$, while the joint housing plus transport expense ratio $\tau_{H T}(r)=(R(r) s+T(r)) / Y$ also includes the transport budget. Last, using the budget constraint from Equation (1), the quantity of composite good consumed by the household is $z=Y-R(r) s-T(r)$. It is the income minus housing costs $R(r) s$ and transport costs $T(r)$. Based on the literature review from Section 2, we can interpret $z$ as the household's residual income. Accordingly, we refer to the $z$ expense ratio given by $\tau_{z}(r)=z / Y$ as the household's solvency level. A high value of $\tau_{z}(r)$ indicates a low risk of default (the household living at location $r$ has a large share of its income available to meet other daily expenses besides housing and transport), and conversely. Using $z=Y-R(r) s-T(r)$, the housing plus transport burden $\tau_{H T}(r)$ and the solvency level $\tau_{z}(r)$ are straightforwardly related by: $\tau_{z}(r)=1-\tau_{H T}(r)$. 
In the remainder of the text, we use the monocentric model to study how the solvency level $\tau_{z}(r)$ varies with location for the low-income group. ${ }^{10}$ We first consider the unregulated (or unconstrained) case (Section 4), then the case of $\mathrm{CH}$ (Section 5) and CHT policies (Section 6). To keep the model simple, we do not explicitly model the situation of default - in which the household ceases to pay its rent or to reimburse its loan - and its consequences such as possible eviction. ${ }^{11}$ Rather, we consider that the equilibrium solvency level correctly captures the risk of default, ${ }^{12}$ but that the risk remains sufficiently low within the whole population so that we may neglect its impact on the equilibrium solution. Similarly, households do not take the risk of default into account in their location choice (i.e. the risk of default is not part of the household utility maximization program). This assumption is empirically supported by the work of Hanna et al. (2012), who show that households are willing to accept excessive financial burdens because they do not fully understand (or correctly appraise) the risk of insolvency.

\subsection{Model specification}

To simplify the exposition, we will now specify the utility, transport cost and land supply functions. This makes the algebra simpler while bearing little influence on the main results (except for the choice of the utility function, which is discussed below). We consider the Stone-Geary utility function:

$$
U(z, s)=\left(s-s_{0}\right)^{\alpha}\left(z-z_{0}\right)^{1-\alpha},
$$

where $s_{0} \geq 0$ and $z_{0} \geq 0$ are minimum levels of land and composite good consumption, respectively, and $\alpha$ is a preference parameter satisfying $0<\alpha<1$. In the special case $s_{0}=0$ and $z_{0}=0, U(z, s)$ degenerates to a Cobb-Douglas function, and $\alpha$ represents the fraction of income spent on housing. Although the Cobb-Douglas utility function tends to prevail in the monocentric literature (e.g. Anas et al., 2000; Kilani et al., 2010), the Stone-Geary utility function provides a more general formulation. More specifically, it allows us to specify basic needs for housing $\left(s_{0}\right)$ as well as for other goods $\left(z_{0}\right)$, in consistency with the basic needs approach used in the poverty literature (Galtung, 1979; Ghai, 1978).

\footnotetext{
${ }^{10}$ The analysis focuses on the low-income group as the group with the higher risk of default (Kaza et al., 2016). Findings relative to the high-income group are not presented here for the sake of concision.

${ }^{11}$ Doing so would involve using a stochastic modelling framework, where households face random events that positively or negatively affect their financial capacity (e.g. job loss, child birth, unexpected expenses, and so on). The situation of default would arise in cases where the household faces such adverse events that it is no longer able to cope financially. Such a model would be extremely complex however, while not providing much additional insights compared to our simplified model.

${ }^{12}$ To be specific, we implicitly assume that the risk of default is a function $\varphi(z / Y, Y)$ that strictly decreases and is convex in both $z / Y$ and $Y$. All other things being equal, low-income households have a higher risk of default than high-income households, and low solvency levels lead to a higher risk of default than high solvency levels. Convexity of $\varphi$ implies that if two population groups have the same solvency level on average, the group with the greater dispersion of $z / Y$ has a higher risk of default on average than the group with homogeneous $z / Y$.
} 
We consider linear transportation costs, with $T(r)=a r$. In addition to making the algebra simpler, the linear specification was shown to produce realistic results for the Paris region (Viguié et al., 2014). The fact that transport is represented using a unique cost function does not necessarily imply that a single mode is considered. Rather, this synthetic cost function represents the average transport budget that a household faces when locating at a given location, be it by car, public transport, walk ... ${ }^{13}$

Regarding land supply, we consider a linear city with $L(r)=1$. Again, this specification firstly intends to make the model more analytically tractable. ${ }^{14}$ It is eventually replaced with a more realistic housing supply function à la Muth in our numeral application to the Paris region (Section 8).

Last, two technical assumptions prove necessary later in the text. First, the income level must satisfy $Y>z_{0}+\left(R_{A}+a N\right) s_{0}$. Otherwise, households living near the city center (at $\left.r=0\right)$ cannot meet their basic needs $s_{0}$ and $z_{0}$ and no equilibrium is feasible. We also impose $z_{0} \leq(1-\alpha) R_{A} s_{0} / \alpha$ so that the various expense ratios decrease with income, in accordance with empirical findings (cf. subsection 4.2).

\section{Analysis of the unregulated case}

This section reviews the standard unregulated (or unconstrained) case in which households freely choose their housing and housing plus transport expense ratios, with no upper thresholds on these ratios. As the standard unconstrained case has been largely addressed in the literature, all results from this section may be found in (or easily derived from) reference textbooks such as Fujita (1989).

\subsection{Case with a single income class}

We start with the simple case where all households have the same income $Y$. The bid-max variables, i.e. the triplet $\{\Psi(r, u), s(r, u), z(r, u)\}$ solution to the bid-max problem (2), are given by:

$$
\left\{\begin{array}{l}
u \Psi(r, u)^{\alpha}+A s_{0} \Psi(r, u)=\mathrm{A}\left(Y-z_{0}-a r\right), \\
s(r, u)=s_{0}+\alpha \frac{\left(Y-z_{0}-a r-\Psi(r, u) s_{0}\right)}{\Psi(r, u)}, \\
z(r, u)=z_{0}+(1-\alpha)\left(Y-z_{0}-a r-\Psi(r, u) s_{0}\right),
\end{array}\right.
$$

with $A=\alpha^{\alpha}(1-\alpha)^{1-\alpha}$ (see Proof in Appendix).

\footnotetext{
${ }^{13}$ Following Anas and Moses (1979), it is possible to consider several transport modes in the monocentric model. Doing so allows to derive more realistic urban forms (e.g. finger plans), but at the cost of a much greater analytical complexity and for virtually no changes in the basics of the model. Indeed, whatever the transport cost function $T(r)$ considered, one may always reparametrize the problem to that of a linear transport cost function by applying the following transformation to land supply: $\tilde{L}(r)=L \circ T^{-1}(r)$, where $L(r)$ is the original land supply function, and $\tilde{L}(r)$ the equivalent function in the linearized problem (Arnott and Stiglitz, 1981).

${ }^{14}$ See Coulombel (2016) for an illustration of the (limited) role of housing supply in the single household case.
} 
If $s_{0}>0$, the system (6) does not have a closed form solution because of the bid rent equation, except for specific values of $\alpha$ (e.g. $\alpha=1 / 2$ or $\alpha=1 / 3$ ). Notwithstanding, whatever the value of $s_{0}$, the bid-max variables have the following properties as shown in Fujita (1989): ${ }^{15}$

- the bid rent $\Psi(r, u)$ decreases with distance $r$ to the CBD and with utility $u$;

- the lot size $s(r, u)$ increases with $r$ and $u$;

- the consumption of the composite good $z(r, u)$ decreases with $r .^{16}$

As one gets farther from the $\mathrm{CBD}$, housing prices decrease in response to greater transport costs. Given that housing is cheaper, households far from the CBD choose bigger lot sizes and conversely smaller levels of $z$ good consumption than households close to the CBD (Hicks substitution effect). Using simple assumptions, the monocentric model reproduces two widespread features of cities, namely that housing prices and densities both decrease with distance to the CBD (Anas et al., 1998).

Combining ( 3 ) and (6) yields the housing expense ratio:

$$
\tau_{H}(r)=\frac{R(r) s}{Y}=\alpha+\frac{(1-\alpha) R(r) s_{0}-\alpha z_{0}-\alpha a r}{Y} .
$$

The housing burden is not exactly $\alpha$ as in the standard Cobb-Douglas case, for two reasons. First, the transport cost ar reduces the discretionary income, which mechanically lowers the housing burden. The basic needs $s_{0}$ and $z_{0}$, by setting minimum consumption levels for housing and for the composite good, also mechanically raise and lower, respectively, $\tau_{H}(r)$.

The housing plus transport burden $\tau_{H T}(r)$ is given by:

$$
\tau_{H T}(r)=\frac{R(r) s+T(r)}{Y}=\alpha+\frac{(1-\alpha)\left(R(r) s_{0}+a r\right)-\alpha z_{0}}{Y}
$$

Last, the solvency level is equal to one minus the housing plus transport burden:

$$
\tau_{z}(r)=\frac{z}{Y}=1-\tau_{H T}(r)=1-\alpha+\frac{\alpha z_{0}-(1-\alpha)\left(R(r) s_{0}+a r\right)}{Y} .
$$

\section{Lemma 1}

In the unconstrained monocentric model, the housing burden decreases with distance to the CBD, whereas the housing plus transport burden increases (causing the solvency level to decrease).

\footnotetext{
${ }^{15}$ Alternatively, these properties may be proved here directly by deriving (6) with respect to $r$ and $u$. If $s_{0}=0$, the system (6) can be solved analytically, in which case the properties are readily seen.

${ }^{16}$ There is no specific result regarding the influence of $u$ on $z(r, u)$.
} 


\section{Proof}

See Appendix.

Lemma 1 is in line with the intuition that some households settle far from the city center to lower the housing burden. ${ }^{17}$ Despite this, the household solvency level decreases with distance to the CBD. Greater transport costs in suburban areas more than counterbalance the lower housing costs, leading to greater housing plus transport burdens, and thus lower solvency levels (as $\tau_{z}(r)=1-\tau_{H T}(r)$ ). The predictions of the monocentric model are in line with the empirical literature, as several works find that the housing plus transport burden does increase with distance to the city center (see Section 2). Figure 1 illustrates the above results for the following numerical application: $Y=1000, N=1, \alpha=0.5$, $s_{0}=20, z_{0}=100, a=10$ and $R_{A}=5 .^{18}$

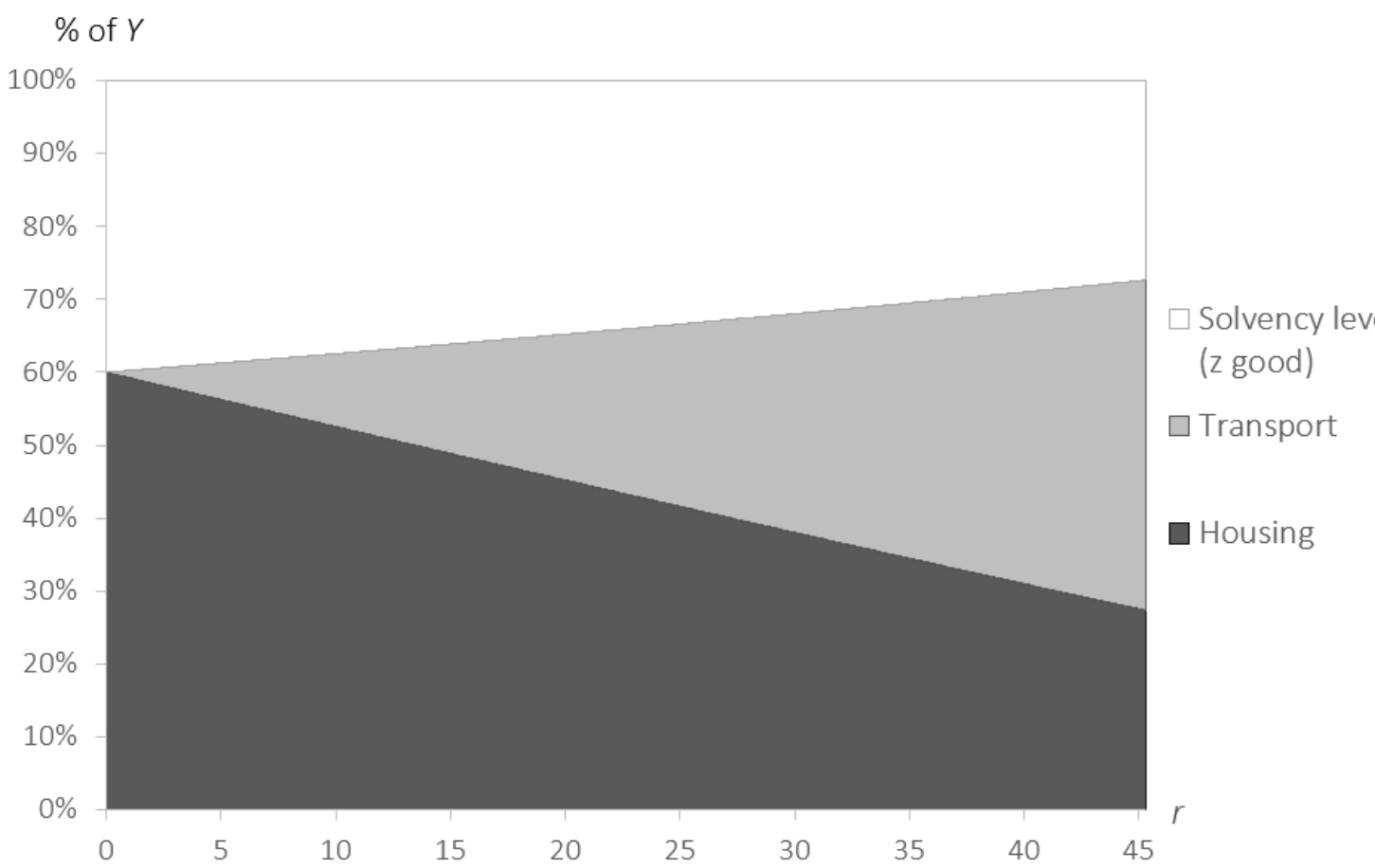

FIGURE 1: EVOLUTION OF THE HOUSEHOLD BUDGET ALLOCATION WITH DISTANCE TO THE CBD

All in all, in the unregulated situation, suburban households are more vulnerable than those living near the city center, and doubly so: they have lower solvency levels, and face greater transportation costs to boot, making them especially sensitive to fuel price spikes.

We now investigate how the analysis varies in the presence of income heterogeneity.

\footnotetext{
${ }^{17}$ This result is relatively general and holds for most regular utility functions (Coulombel, 2010).

${ }^{18}$ While this numerical application aims to be representative of the general case and to illustrate our findings in a simple way, the parameter values and the resulting figures are by no means representative of real case studies. A more realistic application to the Paris region is carried out in Section 8.
} 


\subsection{Case with two income classes}

Consider two types of households: low-income households and high-income ones, characterized by superscripts $P$ and $R$. It is straightforward to show that for each income class, the variational properties of the bid-max variables and expense ratios remain the same as in the case with a single income class. The influence of income on the various expense ratios is provided by Lemma 2.

\section{Lemma 2}

In the unconstrained monocentric model, the housing plus transport burden decreases with income at any city location (meaning that the solvency level increases with income).

If $s_{0}>0$, the housing burden decreases with income near the CBD, then increases beyond a certain distance $r_{H}$. If $s_{0}=0$, the housing burden increases with income at any location.

\section{Proof}

See Appendix.

If $s_{0}>0$, both the housing and the joint housing plus transport burden decrease with income (except possibly within a second, suburban ring for the former). This is in line with empirical findings: several studies bring to light the marked decrease of the two expense ratios ( $\mathrm{H}$ and $\mathrm{HT}$ ) with income. ${ }^{19}$ Conversely, the case $s_{0}=0$ implies that the housing burden increases with income for any location. Although both cases $s_{0}=0$ and $s_{0}>0$ are considered in the remainder of the text, the opposition with empirical findings in the case $s_{0}=0$ challenges the use of standard Cobb-Douglas preferences when considering income heterogeneity in the monocentric model.

Considering differences in income, one might expect the wealthiest households to use their greater financial capacity to outbid low-income households and settle in the most accessible parts of the city. It is actually the opposite that occurs. Low-income households being more sensitive to transport costs, their willingness-to-pay to live near the CBD exceeds that of high-income households. This point is formally given by the following condition on the relative steepness of the bid-rent functions:

$$
\left|\Psi_{r}^{R}\left(r_{P / R}, u_{e}^{R}\right)\right|<\left|\Psi_{r}^{P}\left(r_{P / R}, u_{e}^{P}\right)\right|
$$

where the subscript $r$ denotes the partial derivative with respect to $r$ and $r_{P / R}$ is the border between low- and high-income households. As a result, low-income households live in a first ring near the CBD, while high-income households enjoy bigger lot sizes in a second, suburban ring (Figure 2).

\footnotetext{
${ }^{19}$ See for instance Berri (2007) and Coulombel and Leurent (2013) for France or Haas et al. (2006) and Hickey et al. (2012) for the U.S.
} 


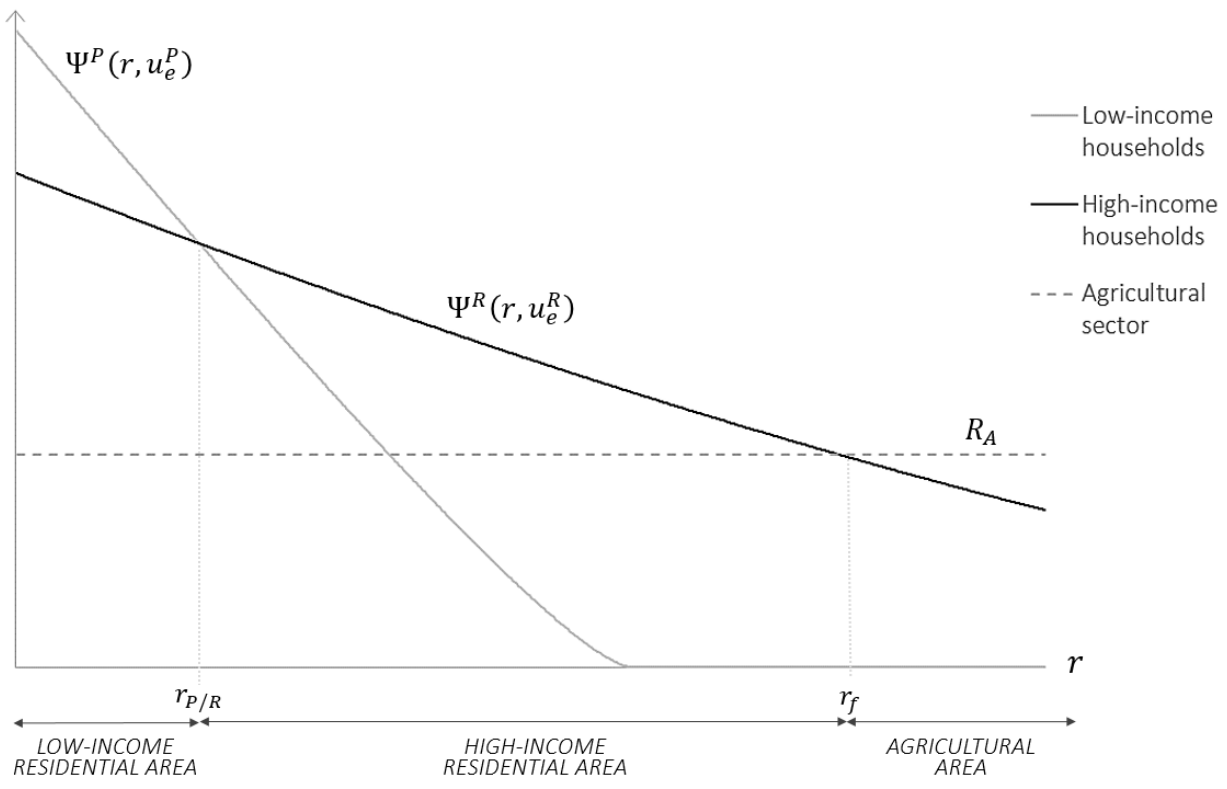

FIGURE 2: BID RENT FUNCTIONS AND THE RING-SHAPED CITY STRUCTURE

The analysis of income heterogeneity has brought to light two opposite mechanisms regarding household solvency: the solvency level increases with income at any given location, but the spatial income sorting phenomenon implies that low-income households live in the central parts of the city, which improves their solvency (relatively to a situation in which they would live in the suburbs).

Figure 3 illustrates the previous findings for the same numerical application as in 4.1 except that there are now two income classes: $Y^{P}=1000, Y^{R}=2000, N^{P}=0.5$ and $N^{R}=0.5$. The first ring consists of low-income households, the solvency of which weakens as one gets farther from the CBD due to the heavier transportation burden (Lemma 1). When reaching the high-income residential area, the rise in income causes a discontinuous jump in the household solvency, which improves (Lemma 2). But again, transport costs entail a deterioration of household solvency with distance to the CBD.

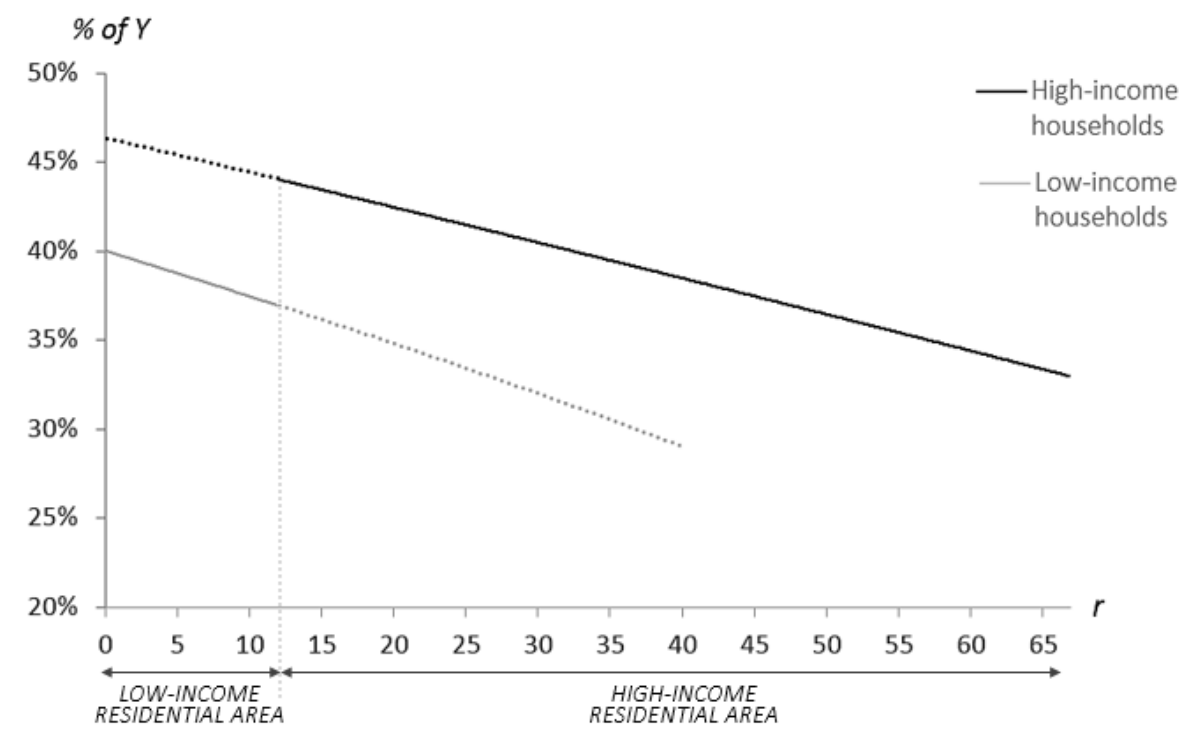

FIGURE 3: EVOLUTION OF THE HOUSEHOLD SOLVENCY LEVEL WITH DISTANCE TO THE CBD 


\section{Analysis of $\mathrm{CH}$ prudential measures}

This section studies the effects of $\mathrm{CH}$ policies using the monocentric model with two income classes. In particular, we seek to assess the claim that capping the housing burden would spur low-income households to settle far from the city center in order to fulfill their housing needs, and would ultimately jeopardize their solvency due to the high transport costs that remote locations involve.

We first present the $\mathrm{CH}$ monocentric model and compare its main properties with the unregulated case treated in Section 4. We then study the influence of the $\mathrm{CH}$ constraint level on the welfare and the solvency of low-income households. Unlike the single income class case which can be treated analytically (see Coulombel, 2016), the case with two income classes proves more complex to handle. Accordingly, several findings are actually conjectures, confirmed over a wide array of numerical values, but which could not be proved in the general case. This limitation only concerns the $\mathrm{CH}$ case, however. As we will see in Section 6, in the CHT case the algebra is simpler and all results are properly established. For disambiguation, a hat symbol " $\wedge$ " will be used when necessary to refer to variables in the $\mathrm{CH}$ case, in contrast to the unconstrained case for which no accentuation is used.

\subsection{The $\mathrm{CH}$ monocentric model}

$\mathrm{CH}$ prudential measures are represented in the monocentric model by adding the following constraint to the household utility maximization problem: ${ }^{20}$

$$
\forall r \in \mathbb{R}^{+}, \hat{\tau}_{H}(r) \leq \delta_{H},
$$

where $\hat{\tau}_{H}(r)=\hat{R}(r) \hat{s} / Y$ is the housing burden and $\delta_{H}$ the required front-end ratio, with $0 \leq \delta_{H} \leq 1$. Using the household budget constraint, $(10)$ is equivalent to:

$$
\hat{\tau}_{z}(r) \geq \bar{\delta}_{H}-\frac{T(r)}{Y},
$$

where $\hat{\tau}_{z}(r)=\hat{z} / Y$ is the household solvency level and $\bar{\delta}_{H}=1-\delta_{H}$. As transport costs $T(r)$ increase with $r$, the solvency requirement is essentially based on a threshold that decreases with distance $r$ to the CBD. In the remainder of the text, we use the parameter $\bar{\delta}_{H}$ to characterize the $\mathrm{CH}$ constraint level. This leads to more intuitive graphic representations than with the parameter $\delta_{H}$ : starting from $\bar{\delta}_{H}=0$, which corresponds to the unconstrained situation, the constraint becomes stronger as $\bar{\delta}_{H}$ increases, with $0 \leq \bar{\delta}_{H} \leq 1$ (whereas it is the opposite with $\delta_{H}$ ).

\footnotetext{
${ }^{20}$ In the monocentric model, the question of who sets the $\mathrm{CH}$ constraint - whether it is landlords, lenders, both, or even households themselves - makes no relevance. For the sake of discussion, and as observed empirically, we assume throughout the paper that it is the capital owners (landlords and lenders) who implement those rules. We elaborate on this point in Section 9.
} 


\subsubsection{Constrained zone}

The constrained zone is defined as the set of locations where the $\mathrm{CH}$ constraint is active (or binding). Equivalently, it is the set of locations where the unconstrained housing expense ratio exceeds the authorized limit $\delta_{H}$.

\section{Lemma 3}

The constrained zone in the $\mathrm{CH}$ case is a disk: $\left\{r \in \mathbb{R}^{+} \mid r \leq \hat{r}_{c}\left(\bar{\delta}_{H}\right)\right\}$. The outer boundary $\hat{r}_{c}\left(\bar{\delta}_{H}\right)$ increases with the constraint level $\bar{\delta}_{H}$.

If the minimum lot size is null $\left(s_{0}=0\right)$, the outer boundary $\hat{r}_{c}\left(\bar{\delta}_{H}\right)$ increases with income $Y$.

\section{Proof}

See Appendix.

The constrained zone is a disk centered on the CBD. For low values of $\bar{\delta}_{H}$, the disk is small and only households living near the CBD (if any) are affected. As $\bar{\delta}_{H}$ increases, the constraint becomes stronger, until eventually covering the whole city (meaning that all households are affected by the constraint). The role of income on the size of the constrained zone is undetermined in the general case, however. If the minimum lot size $s_{0}=0$, the unconstrained housing burden $\tau_{H}(r)$ increases with income $Y$ (Lemma 2), and subsequently so does the size of the constrained zone, which is contrary to intuition. In the more plausible case $s_{0}>0, \tau_{H}(r)$ decreases with $Y$ near the CBD but increases far from the CBD (Lemma 2), hence the indetermination. When $s_{0}$ is large, the size of the constrained zone will typically decrease with income, and vice versa.

All in all, $\mathrm{CH}$ prudential measures firstly target households living in the central parts of the city, where housing costs are high. They induce a centrifugal force pushing households toward the outskirts, where housing is more affordable. The force magnitude varies with income in a non-trivial manner: low-income households are more impacted than high-income ones the closer one is to the CBD and the larger the minimum lot size $s_{0}$ is.

\subsubsection{Bid-max variables}

Because of the $\mathrm{CH}$ constraint, consumption choices vary depending on whether the household is inside or outside the constrained zone. The bid-max variables are given by:

$$
\left\{\begin{array}{l}
\hat{\mathrm{z}}(r, u)=\max \left[z(r, u), \bar{\delta}_{H} Y-a r\right], \\
\widehat{\mathrm{s}}(r, u)=\min \left[s(r, u), s_{0}+u^{\frac{1}{\alpha}}\left(\bar{\delta}_{H} Y-a r-z_{0}\right)^{\frac{\alpha-1}{\alpha}}\right], \\
\widehat{\Psi}(r, u)=\min \left[\Psi(r, u), \delta_{H} Y / \widehat{s}(r, u)\right] .
\end{array}\right.
$$


From (12) it is straightforward to show that $\hat{\mathrm{z}}(r, u) \geq z(r, u), \hat{\mathrm{s}}(r, u) \leq s(r, u)$ and $\widehat{\Psi}(r, u) \leq \Psi(r, u)$. Because $\mathrm{CH}$ prudential measures limit the household bidding capacity, they lead to lower bid rents, smaller lot sizes, and conversely to greater consumptions of the $z$ good within the constrained zone. ${ }^{21}$ Figure 4 illustrates these various points in the case of our reference numerical application and of the low-income group for $\bar{\delta}_{H}=0.4$ and $u=214.547 .^{22}$

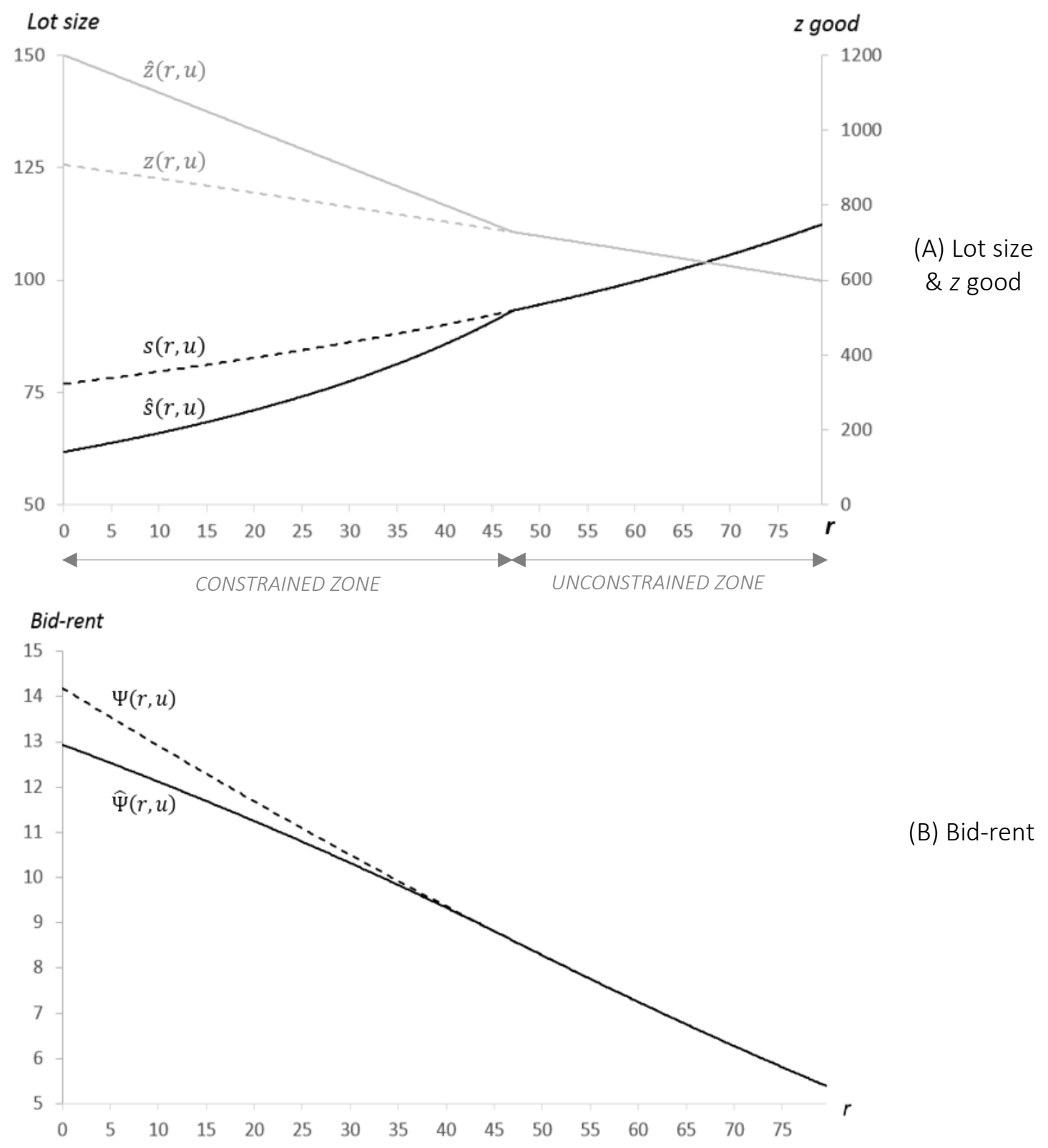

FIGURE 4 : INFLUENCE OF THE CH CONSTRAINT ON BID-MAX VARIABLES

\footnotetext{
${ }^{21}$ This is for a given utility level. Because the $\mathrm{CH}$ constraint changes the equilibrium utility level of the city, we will see that $\mathrm{CH}$ policies may ultimately lead to larger lot sizes than in the unconstrained city.

${ }^{22}$ The value $u=214.547$ corresponds to the equilibrium utility of the low-income group in the single class case, i.e. when $N_{P}=1$ and $N_{R}=0$.
} 


\subsubsection{Income sorting}

As discussed in 4.2, the location of each income class depends on the relative steepness of their bid rent functions. In the unregulated case, the bid rent function of the low-income group is always steeper than that of the high-income group. Thus, the former lives near the CBD and the latter in the suburbs. Because $\mathrm{CH}$ measures lower the household bidding power and because the effect varies with income, the relative steepness of the bid rent functions might change as a result, in which case the locations of the two groups could be inverted: low-income households would live in the suburbs and high-income ones near the CBD. This is indeed what we observe numerically when $s_{0}>0$, but never when $s_{0}=0$. This leads us to the following proposition and conjecture for the cases $s_{0}=0$ and $s_{0}>0$, respectively (as we could not complete the proof for the latter case)

\section{Proposition 1}

If the minimum lot size is null $\left(s_{0}=0\right)$, the relative location of each income group remains unchanged, whatever the constraint level.

\section{Conjecture 1}

If the minimum lot size is strictly positive $\left(s_{0}>0\right)$, the low-income group is progressively pushed toward the city outskirts as the $\mathrm{CH}$ constraint increases.

\section{Proof}

See Appendix.

Figure 5 illustrates our conjecture for our reference numerical application (from subsection 4.2). ${ }^{23}$ As the $\mathrm{CH}$ constraint becomes stronger (i.e. $\bar{\delta}_{H}$ increases), the bidding power of each groups declines, especially so for the low-income one. For high values of $\bar{\delta}_{H}$ (here $\bar{\delta}_{H}=0.85$ ), high-income households outbid low-income ones near the CBD, and the latter are pushed progressively toward the suburbs. For very high values of $\bar{\delta}_{H}$ (here for $\bar{\delta}_{H}=0.875$ ), income-location patterns are completely reversed: the high-income households all live near the city center, whereas all low-income households live in an outer suburban ring.

\footnotetext{
${ }^{23}$ For reminder, the parameter settings are: $Y^{P}=1000, Y^{R}=2000, N^{P}=0.5, N^{R}=0.5, \alpha=0.5, s_{0}=20$, $z_{0}=100, a=10$ and $R_{A}=5$.
} 


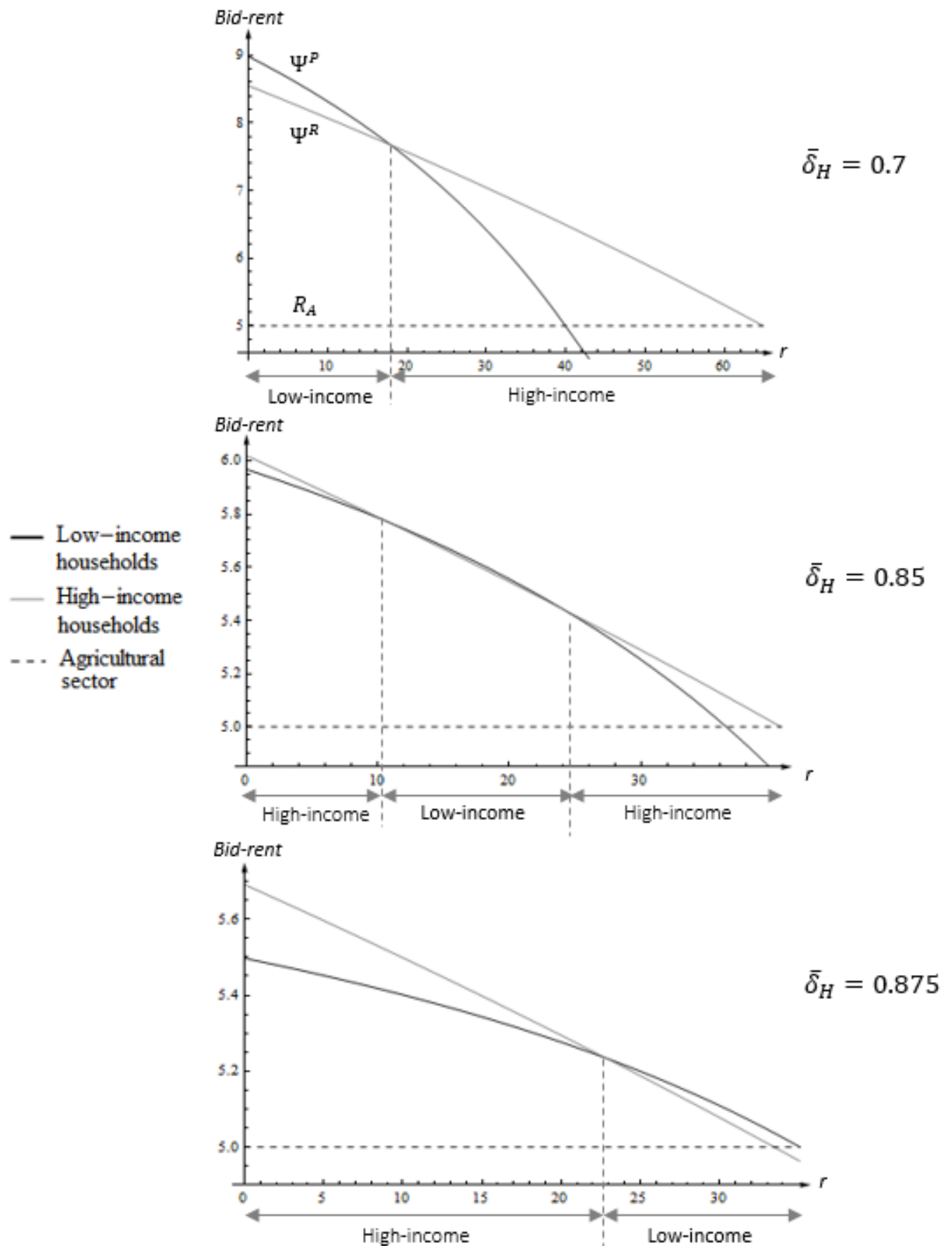

FIGURE 5: INFLUENCE OF THE CH CONSTRAINT LEVEL ON EQUILIBRIUM LOCATIONS

\subsection{Comparative statics}

Using the previous results, we investigate the effects of $\mathrm{CH}$ prudential measures on the household welfare (as measured by its equilibrium utility level) and the household solvency (as measured by $\tau_{z}$ ). As stated in Introduction, the analysis focuses on low-income households. In particular, we investigate whether the $\mathrm{CH}$ constraint does indeed protect the solvency of these households as it is intended to. To do so, we carry comparative statics: we study the influence of the $\mathrm{CH}$ constraint level $\bar{\delta}_{H}$ on the equilibrium utility of the low-income class, then on its solvency. 


\subsubsection{Household welfare}

The limitation of the front-end ratio induces two opposite forces regarding the equilibrium utility. For a given land rent level, households achieve a lower utility than when they are unconstrained (because the $\mathrm{CH}$ constraint - when binding - forces them to make sub-optimal choices). But because capping housing expenses limits the household bidding power, it has a depressing effect on bid prices, hence on equilibrium land rents, which tends to raise household utility (through an income effect). Depending on the relative magnitude of the two forces, the utility level in the $\mathrm{CH}$ case will be higher or lower than in the unregulated case. Like in the $\mathrm{CH}$ case with a single income class (Coulombel, 2016), we find based on extensive numerical analysis that the equilibrium utility of the low-income group remains constant if the constraint is weak (and thus ineffective), rises if the constraint is moderate, but decreases if the constraint is too strong. This leads us to the following conjecture:

\section{Conjecture 2}

As the $\mathrm{CH}$ constraint increases, the equilibrium utility of the low-income class remains constant at first, then strictly increases, and eventually strictly decreases.

Again, Figure 6 corroborates our conjecture by illustrating the case of our reference model. While the same pattern is always observed for the low-income class, whatever the parameter values, the high-income class features two different patterns depending on the income differential. If $Y^{R} \gg Y^{P}$, the equilibrium utility $\hat{u}_{e}^{R}$ of the high-income group is constant then strictly increases. If the differential is moderate or small, the equilibrium utility follows the pattern seen in Figure 6: it is constant at first, strictly increases, but then strictly decreases if the $\mathrm{CH}$ constraint is too strong.

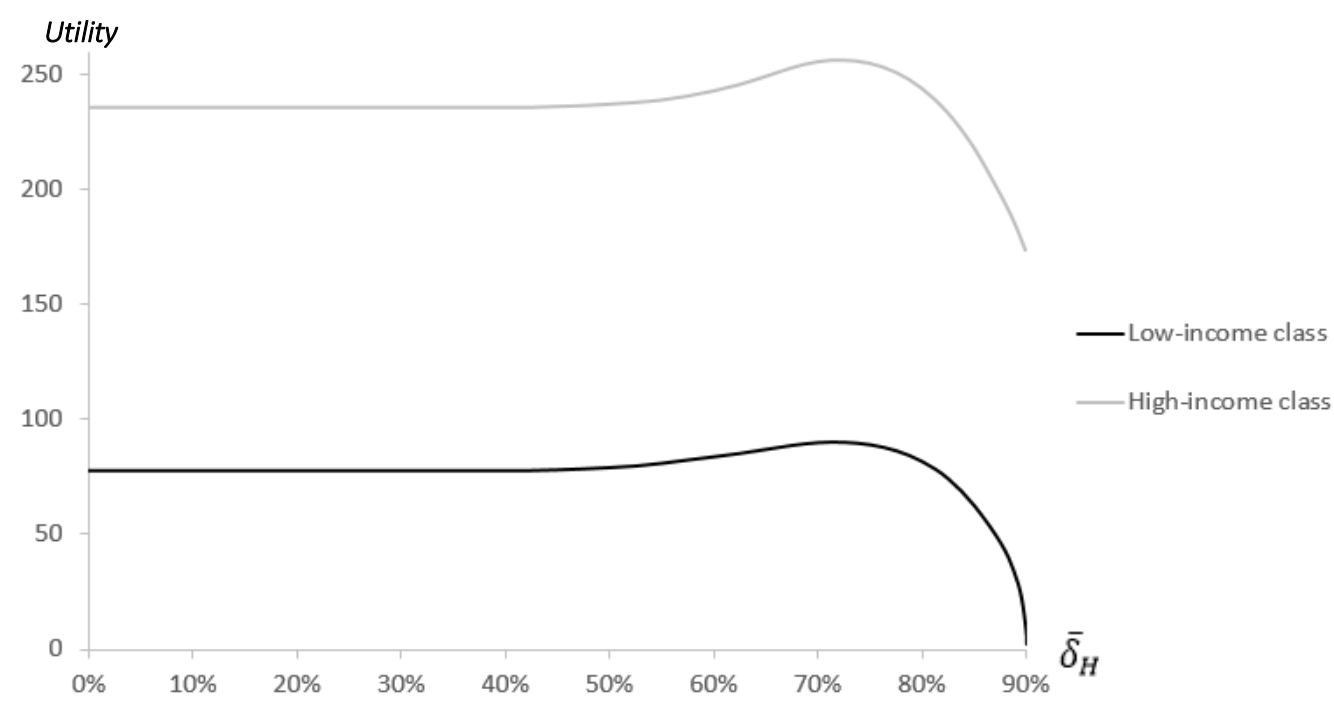

FIGURE 6: INFLUENCE OF THE CH CONSTRAINT LEVEL ON EQUILIBRIUM UTILITIES 


\subsubsection{Household solvency}

$\mathrm{CH}$ prudential measures seek to decrease the risk of insolvency by capping the household's housing budget at a given fraction of its income, so that the remaining income share may cover other expenses. As long as the $\mathrm{CH}$ constraint is moderate, the solvency effect does operate and we see an improvement in the solvency of both low- and high-income households. If the $\mathrm{CH}$ constraint is too strong however, low-income households are progressively evicted from the central parts of the city and thus face a strong increase in their transport costs. As a result, their solvency deteriorates instead of improving. This phenomenon does not occur if $s_{0}=0$ however, as the eviction mechanism does not operate (Proposition 1). This leads us to the following conjecture.

\section{Conjecture 3}

As the $\mathrm{CH}$ constraint increases, the mean solvency level of the low-income group rises, then falls at some point if $s_{0}>0$. The range of the solvency level distribution increases then decreases.

To corroborate Conjecture 3, we illustrate the influence of the $\mathrm{CH}$ constraint level on the household solvency distribution for our reference model (Figure 7). If $\bar{\delta}_{H}$ is low, the $\mathrm{CH}$ requirement is loose and no household is constrained: the solvency level distribution remains constant. As $\bar{\delta}_{H}$ increases, the $\mathrm{CH}$ requirement becomes stricter. Low-income households are affected first, then high-income ones too. For each income class, the solvency level of the households closest to the city center starts to improve, which raises the mean and maximum solvency levels, but not the minimum. At first, the improvement of household solvency therefore comes with a rise in inequality (evidenced by the increase in the range of the solvency distribution). As $\bar{\delta}_{H}$ increases further, all households are constrained and the minimum solvency level eventually starts to increase. This also causes the range of solvency levels to decrease.
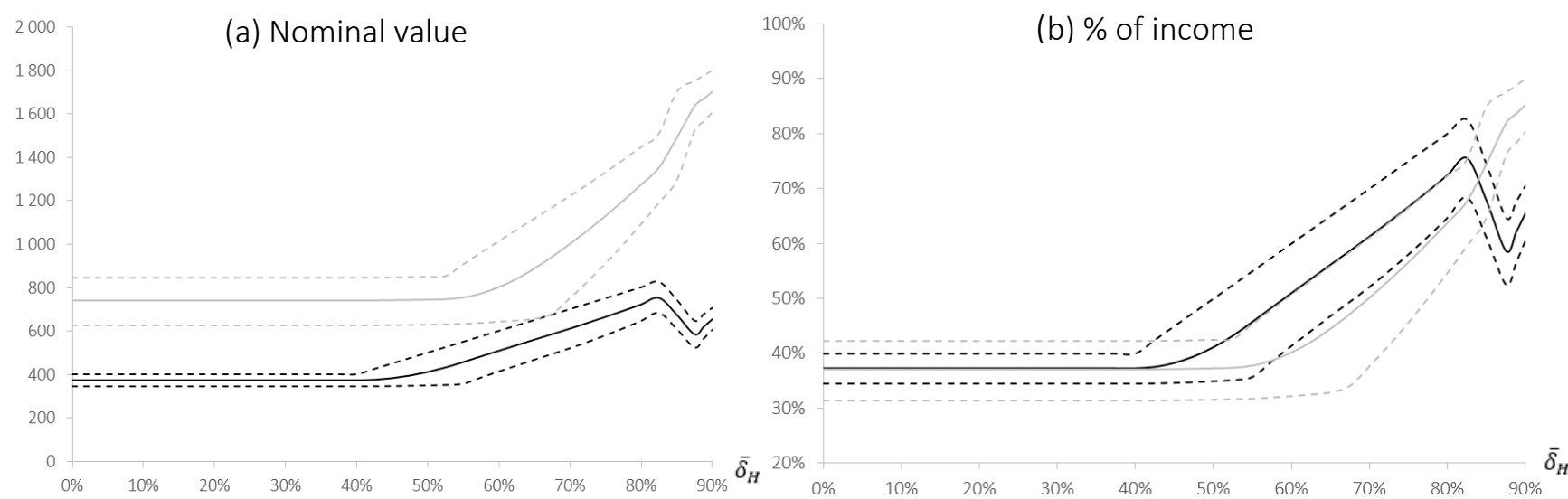

- Low-income class

- High-Income Class

For each Figure, the plain line represents the mean solvency level of the considered income class, whereas the lower and upper dashed lines represent the minimum and maximum solvency levels, respectively. The solvency level is measured either in nominal value (a) or as a fraction of income (b). 
At some point however, the eviction effect takes place and the solvency of low-income households starts to deteriorate. Conversely, high-income households benefit from a marked improvement in their solvency as they move to the central parts of the city. Finally, when $\bar{\delta}_{H}$ nears its maximum value, the eviction mechanism de facto ceases as low-income households have been pushed to the city outskirts, and the solvency of both income categories improves again.

\section{Analysis of $\mathrm{CHT}$ prudential measures}

We now consider the alternative measure that caps the housing plus transport ( $\mathrm{CHT}$ ) expense ratio. As previously, we first review the basic properties of the CHT monocentric model in subsection 6.1, then investigate the effects of $\mathrm{CH}$ prudential measures on low-income households in subsection 6.2. A tilde symbol " " is used when necessary to refer to variables in the CHT case.

\subsection{The CHT monocentric model}

CHT prudential measures institute the following constraint on the household budget allocation:

$$
\forall r \in \mathbb{R}^{+}, \tilde{\tau}_{H T}(r) \leq \delta_{H T} .
$$

The joint housing plus transport expense ratio is capped at a fraction $\delta_{H T}$ of the household income. Using the household budget constraint, (13) can be rewritten as:

$$
\tilde{\tau}_{z}(r) \geq \bar{\delta}_{H T},
$$

where $\bar{\delta}_{H T}=1-\delta_{H T}$. In other words, $\bar{\delta}_{H T}$ sets the minimum solvency level, i.e. the minimum income share that must remain available for the sole consumption of the $z$ composite good. Like in Section 5 , we will henceforward use the parameter $\bar{\delta}_{H T}$ instead of $\delta_{H T}$ to characterize the $\mathrm{CHT}$ constraint level. Starting from $\bar{\delta}_{H T}=0$, which corresponds to the unregulated (or unconstrained) case, the constraint becomes stronger as $\bar{\delta}_{H T}$ increases, with $\bar{\delta}_{H T} \leq 1$.

\subsubsection{Constrained zone}

Unlike $\mathrm{CH}$ measures, $\mathrm{CHT}$ prudential measures firstly target distant households.

\section{Lemma 4}

The constrained zone is a ring $\left\{r \in \mathbb{R}^{+} \mid r \geq r_{c}\left(\bar{\delta}_{H T}\right)\right\}$. The inner boundary $r_{c}\left(\bar{\delta}_{H T}\right)$ increases with income $Y$ and decreases with $\bar{\delta}_{H T}$.

\section{Proof}

See Appendix. 
The constrained zone is an outer ring at first, only households living far from the CBD being affected. As $\bar{\delta}_{H T}$ increases further, the constraint becomes stronger, until all households are eventually affected. Moreover, all other things equal, low-income households are more likely to be limited by the CHT prudential ratio than high-income households.

\subsubsection{Bid-max variables}

In the $\mathrm{CHT}$ monocentric model, the bid-max variables are given by:

$$
\left\{\begin{array}{l}
\tilde{z}(r, u)=\max \left[z(r, u), \bar{\delta}_{H T} Y\right], \\
\tilde{s}(r, u)=\min \left[s(r, u), s_{0}+u^{\frac{1}{\alpha}}\left(\bar{\delta}_{H T} Y-z_{0}\right)^{\frac{\alpha-1}{\alpha}}\right], \\
\widetilde{\Psi}(r, u)=\min \left[\Psi(r, u),\left(\delta_{H T} Y-a r\right) / \tilde{s}(r, u)\right] .
\end{array}\right.
$$

Like $\mathrm{CH}$ prudential measures, $\mathrm{CHT}$ prudential measures lead to smaller home sizes, lower bid rents, and greater consumptions of the $z$ composite good. More specifically, CHT measures de facto enforce both a maximum home size and a minimum solvency level: from (15), $\tilde{z}(r, u)$ and $\tilde{s}(r, u)$ are constant (with respect to $r$ ) within the constrained zone. Furthermore, within the constrained zone we have $\widetilde{\Psi}_{r}(r, u)=-a / \tilde{s}(r, u)$. This implies that Muth's relationship:

$$
\tilde{R}^{\prime}(r)=-\frac{T^{\prime}(r)}{\tilde{s}(r, u)} \forall r \in\left[0, \widetilde{r_{f}}[\right.
$$

remains true in the $\mathrm{CHT}$ case. This key property makes the algebra much simpler than in the $\mathrm{CH}$ case. In particular, it makes the formal derivation of the equilibrium solution feasible.

Figure 8 illustrates these various points in the case of our reference numerical application and of the low-income group for $\bar{\delta}_{H T}=0.4$ and $u=206.559 .{ }^{24}$

\subsubsection{Income sorting}

Using Muth's relationship, we can show that the two income classes appear in the same order as in the unconstrained case.

\section{Proposition 2}

CHT prudential measures preserve the natural income sorting order: low-income households live in the central part of the city, whereas high-income households live in a suburban ring.

\section{Proof}

See Appendix.

\footnotetext{
${ }^{24}$ The value $u=206.559$ corresponds to the equilibrium utility of the low-income group in the single class case, i.e. when $N_{P}=1$ and $N_{R}=0$.
} 


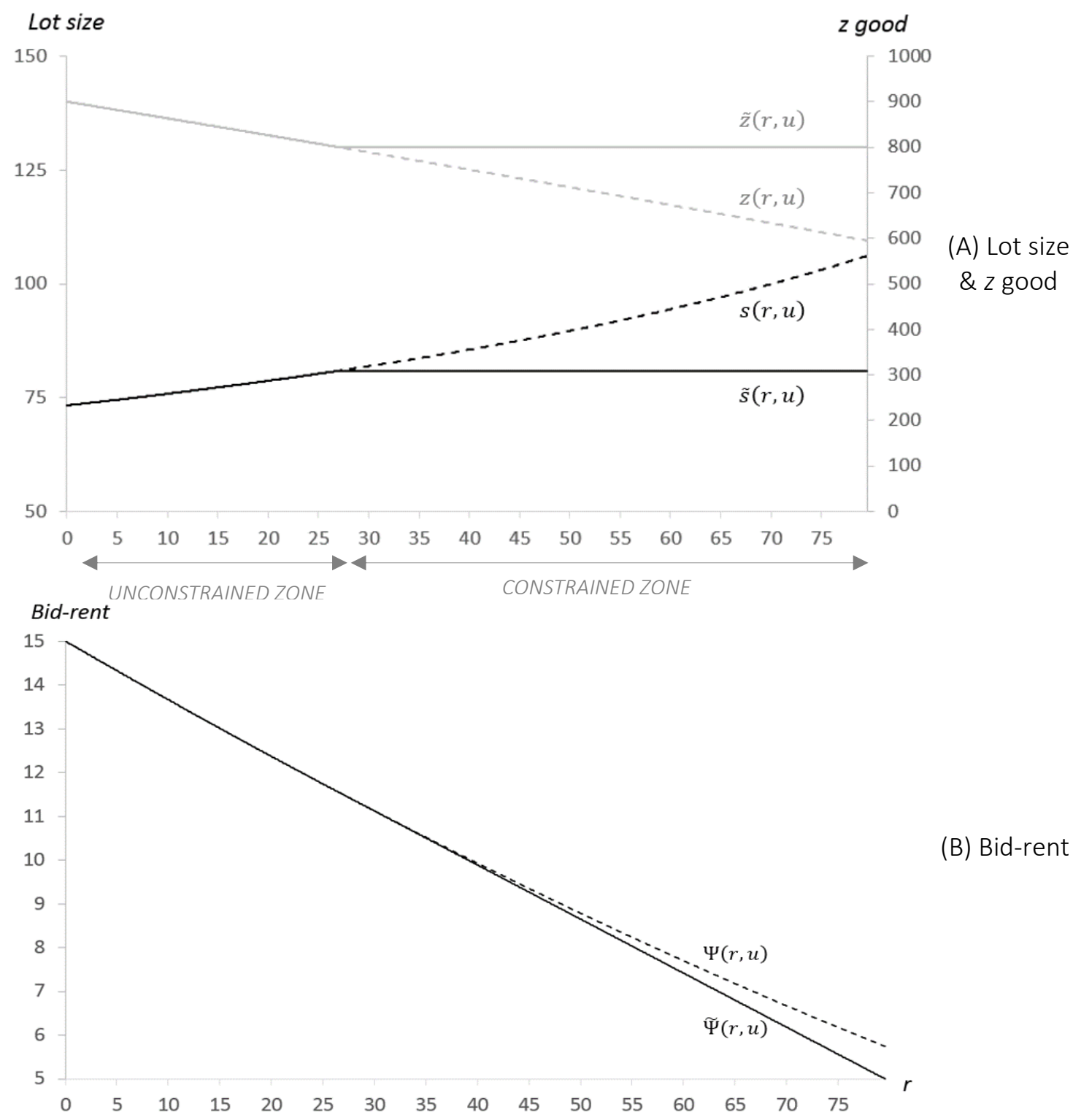

FIGURE 8 : INFLUENCE OF THE CHT CONSTRAINT AND OF LOCATION ON BID-MAX VARIABLES

Unlike $\mathrm{CH}$ prudential measures, $\mathrm{CHT}$ prudential measures do not have the unintended property of pushing low-income households toward the periphery. On the contrary, limiting the housing plus transport expense ratio induces a centripetal force which attracts distant households toward the CBD, where overall housing plus transport costs are lower.

\subsection{Comparative statics}

\subsubsection{Household welfare}

Capping the HT expense ratio induces the same two opposite forces as in the $\mathrm{CH}$ case: for a given level of housing prices the $\mathrm{CHT}$ constraint reduces the maximum reachable utility level (direct effect), but also leads to lower housing prices at equilibrium, which raises the household equilibrium utility (indirect equilibrium effect). The final outcome is provided by Proposition 3. 


\section{Proposition 3}

When the CHT constraint increases, the utility of the low-income group remains constant at first, then strictly decreases above a certain threshold $\bar{\delta}_{H T}^{1}$.

\section{Proof}

See Appendix.

Like in the $\mathrm{CH}$ case, there are three regimes. If the $\mathrm{CHT}$ constraint is too low, it is de facto ineffective and the equilibrium situation is the same as in the unregulated case. For moderate values of the CHT constraint, we observe an effect on high-income households but not on low-income ones (Figure 9). For the latter group, the two opposite forces perfectly compensate each other, and the equilibrium utility remains constant. The former benefit from the weaker competition on the housing market, hence an increase of their utility level. When the $\mathrm{CHT}$ constraint becomes too strong (i.e. $\left.\bar{\delta}_{H T}>\bar{\delta}_{H T}^{1}\right)$, the direct negative effect starts to prevail and the utility of the low-income group falls. Regarding the high-income group, the utility level keeps increasing at first, then may or may not also fall depending on the income differential between the two groups. Here, the income differential remains moderate, so that the utility of the high-income class also falls when the CHT constraint is excessively strong.

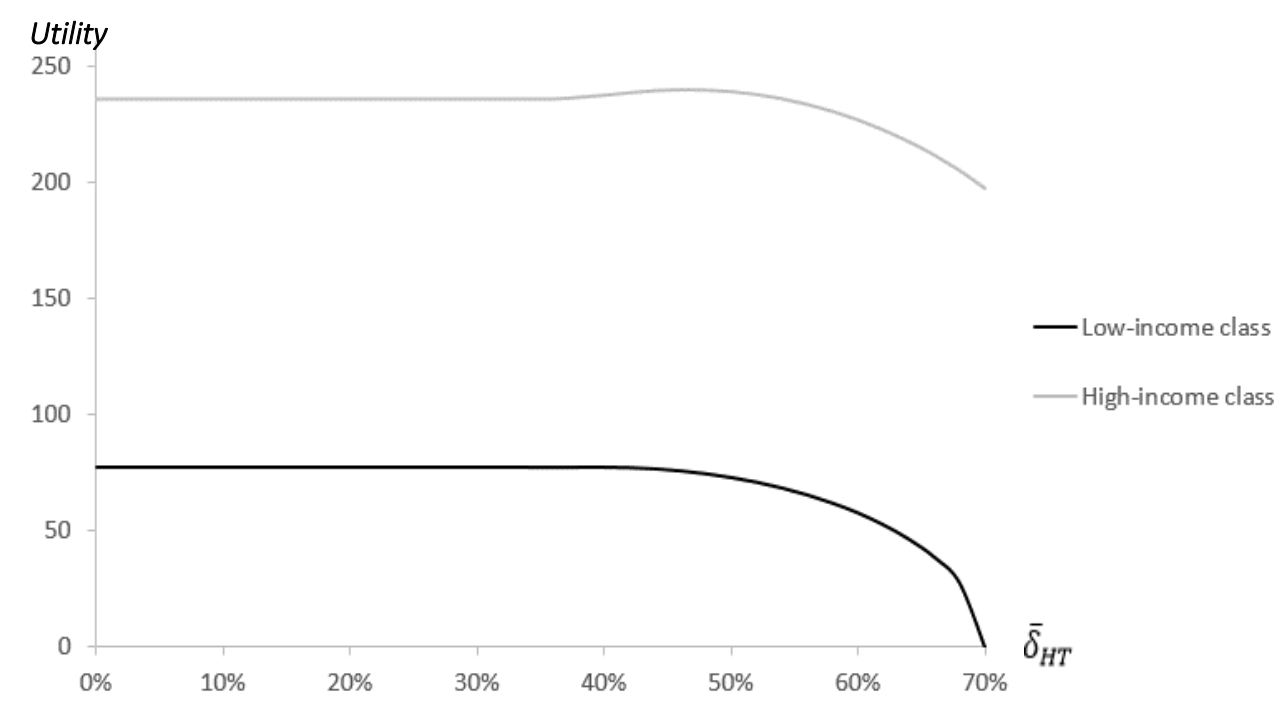

FIGURE 9: INFLUENCE OF THE CHT CONSTRAINT LEVEL ON EQUILIBRIUM UTILITIES

\subsubsection{Household solvency}

Unlike $\mathrm{CH}$ prudential measures, $\mathrm{CHT}$ prudential measures unequivocally improve the solvency of low-income households.

\section{Proposition 4}

Consider the distribution of solvency levels for the low-income class in the CHT monocentric model. If the CHT constraint increases, the mean increases while the range decreases. 


\section{Proof}

See Appendix.

Proposition 4 is almost tautological. Indeed, the $\mathrm{CHT}$ constraint directly bears on the solvency level (based on our definition of this notion) as indicated by (14). It is quite intuitive that increasing the CHT constraint would then improve household solvency. Because of non-trivial equilibrium effects though, this point was not as obvious as it seemed and needed to be properly established. Besides, the fact that the range of the distribution of solvency levels decreases proves that $\mathrm{CHT}$ prudential measures are especially efficient in improving household solvency. In addition to raising the mean solvency level, they also lead to more uniform levels across households hence a better control of risk (Figure 10).

(a) Nominal value

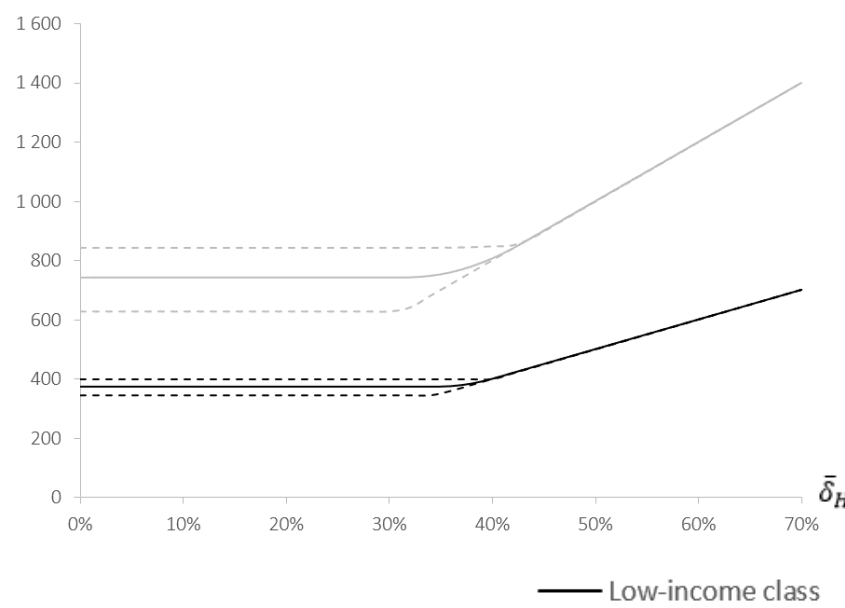

(b) \% of income

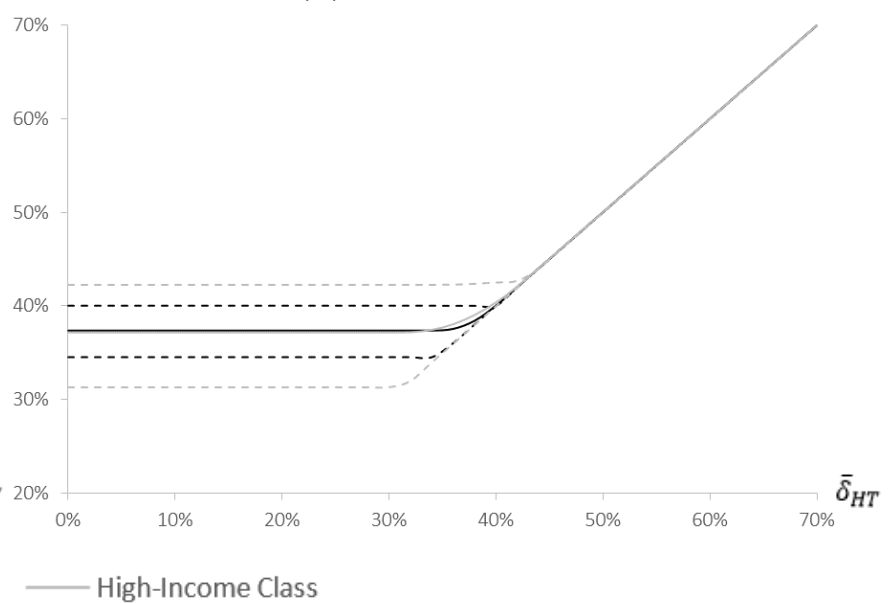

For each Figure, the plain line represents the mean solvency level of the considered income class, whereas the lower and upper dashed lines represent the minimum and maximum solvency levels, respectively. The solvency level is measured either in nominal value (a) or as a fraction of income (b).

\section{FIGURE 10: INFLUENCE OF THE CHT CONSTRAINT LEVEL ON HOUSEHOLD SOLVENCY}

\section{Exploring the influence of variations in transport costs}

We have assumed in the previous sections that transport costs are the same for all households, and are constant over time. This section further investigates the role of transport costs by examining these two assumptions. As a matter of fact, one of the main arguments in favor of $\mathrm{CHT}$ policies is that they supposedly protect low-income households from fuel price spikes. We investigate this first point by considering the effects of an increase in transport costs. Secondly, the assumption of homogeneous transport costs is challenged by the fact that low-income households may develop strategies to cut transport costs (ride sharing, car sharing...). We examine to what extent our conclusions are modified when accounting for this possibility by considering heterogeneous transport costs. 


\subsection{Increase in transport costs}

Consider an increase in transport costs (caused by higher fuel prices, heavier taxes on transport ...). In the short run, we assume housing choices (location and lot size) and housing prices remain constant. Households have not adjusted their housing consumption yet as it typically implies a residential move (other alternatives include renting part of the house, finding a partner/roommate to share housing costs....). Similarly, real estate prices have yet to integrate the new market conditions. Consequently, in the short run the increase in transportation costs results in an equivalent loss of residual income, which lowers the utility of households and impairs their solvency. In the long run, households may modify their housing choices (e.g. by relocating closer to the CBD or opting for a smaller home size), to adapt to the new transport costs, while housing prices vary concomitantly according to the observed changes in demand.

To illustrate the effects of such an increase in transport costs, we simulate a doubling of the unit transport cost from what would be a low-oil-price scenario $(a=5)$ to a high-oil-price scenario $(a=10)$ in our reference numerical application. We examine how the initial equilibrium solution (with $a=5$ ) varies first in the short run (when housing choices and prices are held constant), then in the long run (corresponding to the new equilibrium solution with $a=10$ ) for the $\mathrm{CH}$ and $\mathrm{CHT}$ cases.

We first present the $\mathrm{CH}$ case, and set the $\mathrm{CH}$ constraint level to $\delta_{H}=50 \%$. In the initial situation (before the increase in transport costs), low-income households live in the central part of the city, between $r=0$ and $r=14$ (Figure 11). The equilibrium utility is $\hat{u}_{e}^{P}=54.49$, and the solvency level of low-income households ranges from $43 \%$ to $50 \%$, with a mean solvency level of $46.6 \%$ (Table 1 ). Consider now a doubling of unit transport costs. In the short run, housing choices and housing prices remain the same: the increase in transport costs leads to an equivalent decrease in residual income. Because households far from the CBD (who have greater transport burdens), are more impacted by the increase in transport costs than households close to the CBD (who have lower transport burdens), households are no longer in equilibrium. The utility of low-income households falls, ranging from 54.49 for the closest households (at $r=0$ ) to a minimum of 48.36 for the farthest households (at $r=14$ ). Concomitantly, the solvency of low-income households deteriorates (Table 1). Again, the most distant households are the most impacted, their solvency level falling from $43 \%$ to only $36 \%$. In the long-run, the situation is actually even worse for low-income households. Given the greater transportation costs, each income class seeks to locate closer to the CBD, hence a general increase in bid-rents (Figure 11). High-income households, with their greater financial capacity, come out victorious of this bidding war. They evict low-income households from the city center, who move toward more distant locations (between $r=5.9$ and $r=18.5$ ). Having to bear both higher housing prices and greater transport costs, the new long-run equilibrium utility of the low-income class is 38.29 , even lower than in the short run. Similarly, solvency levels deteriorate further (Table 1). 


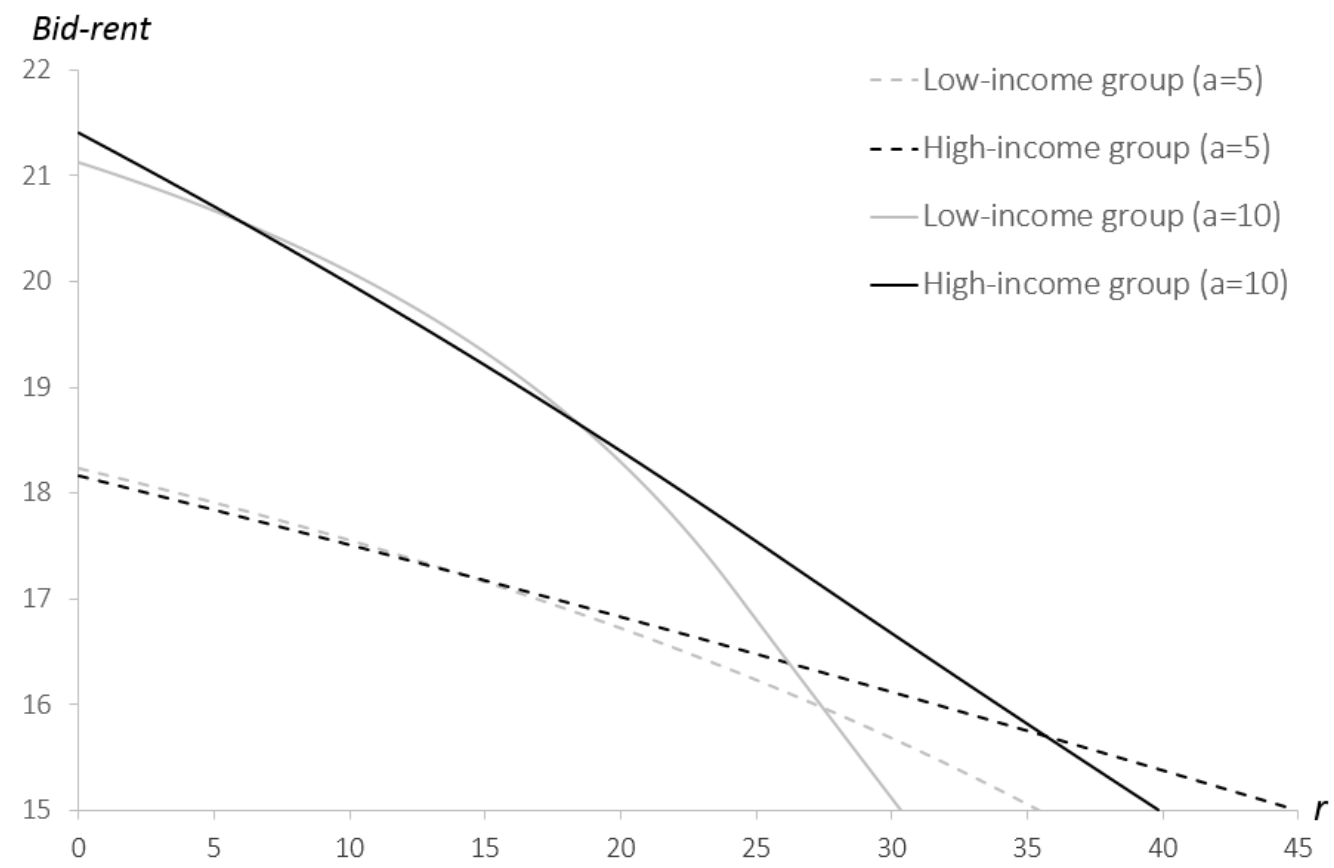

FIGURE 11: INFLUENCE OF A DOUBLING OF UNIT TRANSPORT COSTS ON BID RENTS (CH CASE)

TABLE 1: INFLUENCE ON THE SOLVENCY OF LOW-INCOME HOUSEHOLDS (CH CASE)

\begin{tabular}{|l|c|c|c|}
\hline $\begin{array}{l}\text { Solvency level } \\
\text { (low income group) }\end{array}$ & $\begin{array}{c}\text { Initial situation } \\
\text { (low transport costs) }\end{array}$ & $\begin{array}{c}\text { Short run } \\
\text { (high transport costs, } \\
\text { no housing adjustment) }\end{array}$ & $\begin{array}{c}\text { Long run } \\
\text { (high transport costs, } \\
\text { with housing adjustments) }\end{array}$ \\
\hline Mean & $46.6 \%$ & $43.1 \%$ & $37.9 \%$ \\
\hline Minimum & $43 \%$ & $36 \%$ & $31.5 \%$ \\
\hline Maximum & $50 \%$ & $50 \%$ & $44.1 \%$ \\
\hline
\end{tabular}

To ensure comparability between the $\mathrm{CH}$ and $\mathrm{CHT}$ cases, the constraint level is set to $\delta_{H T}=63.4 \%$ in the $\mathrm{CHT}$ case so that the mean solvency level is ultimately the same (46.6\%) for both initial situations. Like in the $\mathrm{CH}$ case, in the initial situation low-income households live in a (smaller) central ring located between $r=0$ and $r=13.3$ (Figure 12). Their equilibrium utility is equal to 49.54. Furthermore, they all share the same solvency level of $46.6 \%$ (Table 2), resulting from the stringency of the $\mathrm{CHT}$ constraint. Again, the increase in transport costs causes solvency to deteriorate in the short run. The effect is slightly less pronounced than in the $\mathrm{CH}$ case, however (with a mean variation of $-3.3 \%$ against $-3.5 \%$ ). The minimum solvency level is markedly higher to boot ( $40 \%$ in the $\mathrm{CHT}$ case against $36 \%$ in the $\mathrm{CH}$ case), meaning that $\mathrm{CHT}$ policies are likely to limit the number of financially distressed households in the short run by mitigating extreme situations. In the long run, the $\mathrm{CHT}$ constraint perfectly fulfills its role: solvency levels revert back to $46.6 \%$ (corresponding to the minimum allowed by the $\mathrm{CHT}$ constraint), well above the levels observed in the $\mathrm{CH}$ case. This is at the price of a significantly lower utility level, however (22.38 in the $\mathrm{CHT}$ case against 38.29 in the $\mathrm{CH}$ case). 


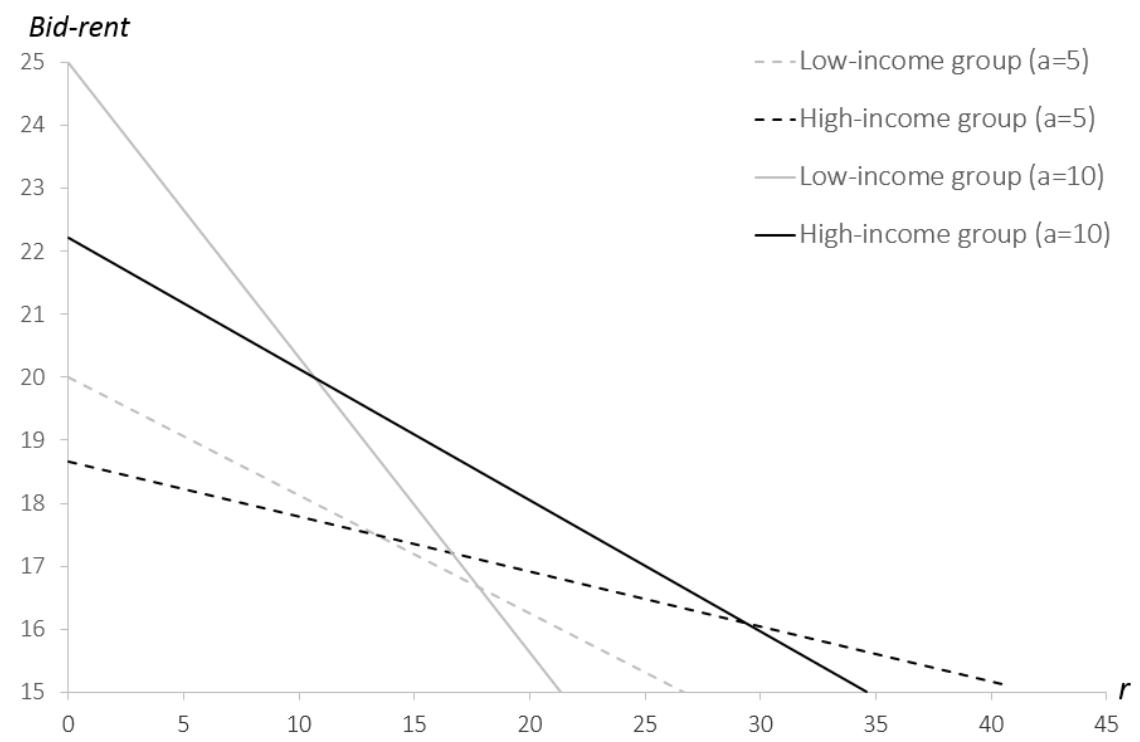

FIGURE 12: INFLUENCE OF A DOUBLING OF UNIT TRANSPORT COSTS ON BID RENTS (CHT CASE)

TABLE 2: INFLUENCE ON THE SOLVENCY OF LOW-INCOME HOUSEHOLDS (CHT CASE)

\begin{tabular}{|l|c|c|c|}
\hline $\begin{array}{l}\text { Solvency level } \\
\text { (low income group) }\end{array}$ & $\begin{array}{c}\text { Initial situation } \\
\text { (low transport costs) }\end{array}$ & $\begin{array}{c}\text { Short run } \\
\text { (high transport costs, } \\
\text { no housing adjustment) }\end{array}$ & $\begin{array}{c}\text { Long run } \\
\text { (high transport costs, } \\
\text { with housing adjustments) }\end{array}$ \\
\hline Mean & $46.6 \%$ & $43.3 \%$ & $46.6 \%$ \\
\hline Minimum & $46.6 \%$ & $40 \%$ & $46.6 \%$ \\
\hline Maximum & $46.6 \%$ & $46.6 \%$ & $46.6 \%$ \\
\hline
\end{tabular}

\subsection{Case of heterogeneous transport costs}

We now investigate the case in which low-income households have lower transportation costs than high-income households. Indeed, low-income households, given their more limited financial capacity, may develop strategies to cut costs such as ride-sharing, car-sharing, resorting more to public transit... We consider heterogeneous transport costs in our reference numerical application, with a high unit cost for high-income households $\left(a^{R}=10\right)$, and a lower unit cost for low-income households $\left(a^{P}=5\right)$. We then compare the equilibrium solution to that found for homogeneous high unit transport costs $\left(a^{P}=a^{R}=10\right)$, to see the influence of cost-cutting strategies from low-income households.

In the $\mathrm{CH}$ case, a decrease in unit transport costs for low-income households (only) leads to flatter bid-rent curves (Figure 13), as expected (cf. Fujita, 1989). Facing lower transport costs, low-income households compete less for locations close to the CBD. They live further in the heterogeneous case (between $r=28.2$ and $r=43.7$ ) than in the homogeneous case (between $r=5.9$ and $r=18.5$ ) as a result. Despite enjoying lower unit transport costs, the fact that low-income households live in more distant locations in the heterogeneous case causes their solvency to deteriorate (Table 3). In the CHT case, similarly the decrease in unit transport costs lead to flatter bid-rent curves. The phenomenon is less pronounced however, so that low-income households remain near the city center (Figure 14). 
Moreover, solvency levels remain unaffected by the change in unit transport costs, as a result of the $\mathrm{CHT}$ constraint. Let us not that in both the $\mathrm{CH}$ and $\mathrm{CHT}$ cases, the decrease in unit transport costs for low-income households leads to a higher utility level (increasing from 38.29 to 49.26 in the $\mathrm{CH}$ case, and from 22.38 to 36.73 in the CHT case).

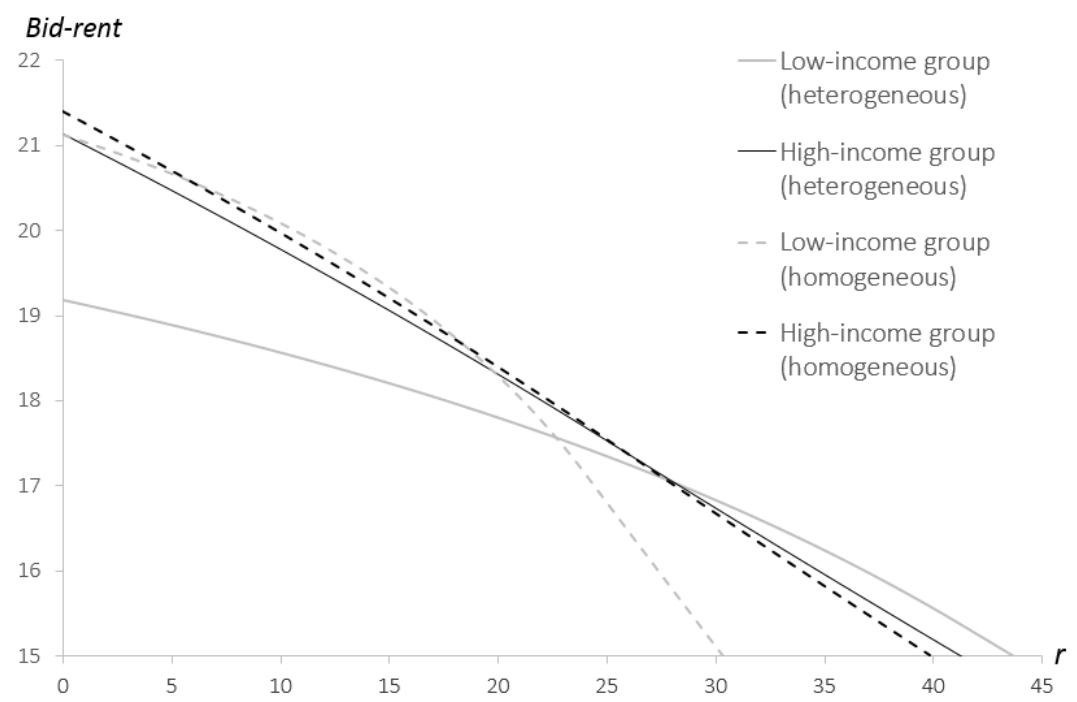

FIGURE 13: INFLUENCE OF HETEROGENEOUS TRANSPORT COSTS ON BID RENTS (CH CASE)

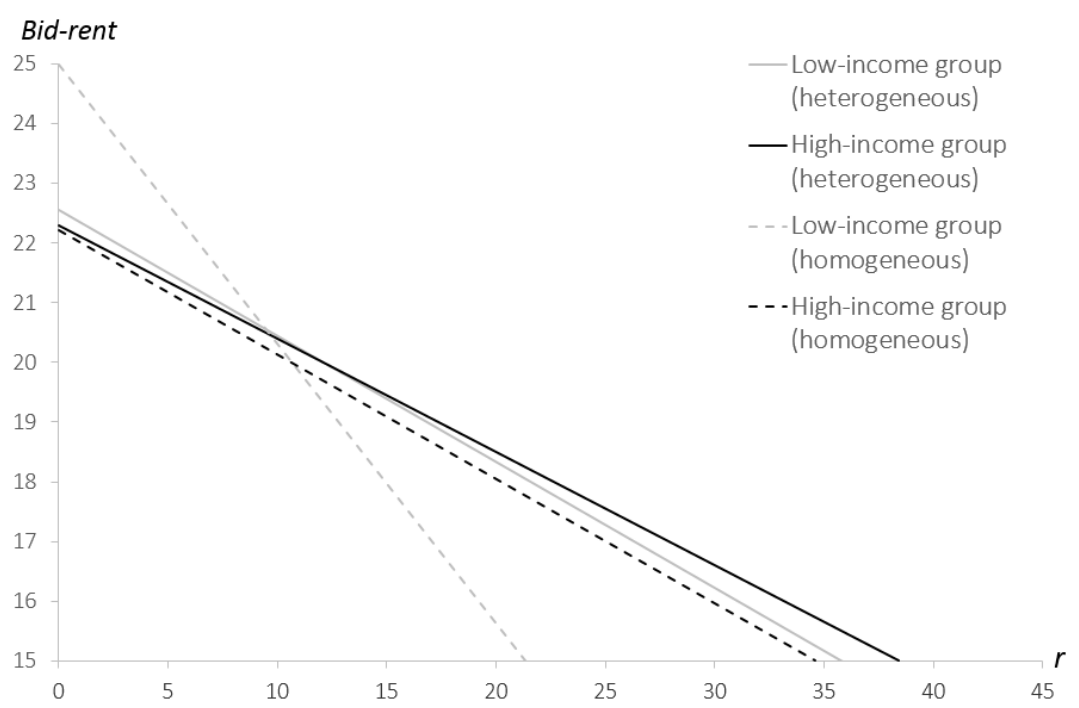

FIGURE 14: INFLUENCE OF HETEROGENEOUS TRANSPORT COSTS ON BID RENTS (CHT CASE)

TABLE 3: INFLUENCE ON THE SOLVENCY OF LOW-INCOME HOUSEHOLDS (CH AND CHT CASES)

\begin{tabular}{|l|c|c|c|c|}
\hline \multirow{2}{*}{$\begin{array}{l}\text { Solvency level } \\
\text { (low income group) }\end{array}$} & $\begin{array}{c}|c| \\
\text { Heterogeneous } \\
\text { transport costs } \\
\left(a^{P}=5, a^{R}=10\right)\end{array}$ & $\begin{array}{c}\text { Homogeneous } \\
\text { transport costs } \\
\left(a^{P}=a^{R}=10\right)\end{array}$ & $\begin{array}{c}\text { Heterogeneous } \\
\text { transport costs } \\
\left(a^{P}=5, a^{R}=10\right)\end{array}$ & $\begin{array}{c}\text { Homogeneous } \\
\text { transport costs } \\
\left(a^{P}=a^{R}=10\right)\end{array}$ \\
\hline Mean & $32.2 \%$ & $37.9 \%$ & $46.6 \%$ & $46.6 \%$ \\
\hline Minimum & $29.1 \%$ & $31.5 \%$ & $46.6 \%$ & $46.6 \%$ \\
\hline Maximum & $35.9 \%$ & $44.1 \%$ & $46.6 \%$ & $46.6 \%$ \\
\hline
\end{tabular}




\section{Application to Île-de-France}

This section develops a short numerical application to île-de-France (the French administrative region in which Paris is located, and which approximately corresponds to the Paris metropolitan area). Rather than providing exact figures, this application intends to illustrate the effects of $\mathrm{CH}$ prudential measures in a real case study, and appraise the potential benefits of a policy change toward CHT rules. The île-de-France is a particularly relevant case study in various regards. First, $\mathrm{CH}$ prudential measures are currently enforced, with a maximum housing expense ratio of around 33\% (see Section 2). Second, the monocentric model is based on the assumption that all jobs are localized at a single point, the CBD. This simplifying assumption underlies the model tractability while making the model easy to interpret. But it may in practice be relaxed and replaced with the (weaker) assumption that commuting costs $T(r)$ increase with distance to the main urban center, regardless of the monocentric or polycentric structure of the metropolitan area. ${ }^{25}$ This is valid for Île-de-France: in the case of median-income households, the mean transportation burden rises from $5 \%$ in inner Paris to $25 \%$ in rural areas for homebuyers, and from $6 \%$ to $16 \%$ for private tenants (Coulombel and Leurent, 2013). Furthermore, the Paris region remains strongly monocentric overall, despite few secondary employment centers (Viguié et al., 2014). Last but not least, housing is expensive, especially in the central parts of the metro area (and firstly Paris), and transport costs in suburban areas are also significant, due to an extensive use of the car. Accordingly, $\mathrm{CH}$ and $\mathrm{CHT}$ policies are likely to matter, especially regarding low-income households.

To yield more realistic results, we extend the monocentric model with two income classes used in the previous sections by introducing the housing industry, in line with the seminal work of Muth (1969). This leads us to substitute the basic land supply function $L(r)=1$ with the more complex housing supply function $H(r)=\theta(r) 2 \pi r * H_{0}\left(\epsilon H_{0} R_{H}(r) / \delta\right)^{\frac{\epsilon}{1-\epsilon}} .^{26}$

Parameter values are collected - or estimated when necessary - from a number of sources and correspond to year 2008. We use Census for household population, and fiscal databases from Insee (the French national institute for statistics) for the household income distribution in the Paris region. The households' Stone-Geary utility function is estimated using the 2006 French Housing Survey.

\footnotetext{
${ }^{25}$ See Coulombel (2010) for more details on this point.

${ }^{26}$ The first term $\theta(r) 2 \pi r$ of the supply equation represents land available at distance $r$ from the CBD $(2 \pi r)$ times the share $\theta(r)$ of land actually allowed to housing (as opposed to other uses such as offices, retail, transport ...). The second term $H_{0}\left(\epsilon H_{0} R_{H}(r) / \delta\right)^{\frac{\epsilon}{1-\epsilon}}$ captures the effect of the housing industry which converts land and capital into housing supply based on expected housing prices $R_{H}(r)$, the cost of capital $\delta$, the elasticity of substitution between land and capital $\epsilon$, and a model constant $H_{0}$. Again, see Coulombel (2010) for more details.
} 
Transport unit costs are derived from Coulombel and Leurent (2013). ${ }^{27}$ The remaining parameters (housing production function, cost of capital) are borrowed from Viguié et al. (2014). ${ }^{28}$ This leads to the following parameter values: $N^{P}=N^{R}=2431000, Y^{P}=1650 €, Y^{R}=4490 €, s_{0}=26.7 \mathrm{~m}^{2}, \alpha=0.136$, $a=0.014 € / \mathrm{km}, \theta(r)=0.5 e^{-r / 5000}, R_{A}=12 € / \mathrm{m}^{2}, H_{0}=2.014, \epsilon=0.36$ and $\delta=5 \%$.

We first analyze the effects of $\mathrm{CH}$ and $\mathrm{CHT}$ prudential measures on household solvency. Increasing the $\mathrm{CH}$ constraint does improve the solvency of low-income households at first (Figure 15). But as the $\mathrm{CH}$ constraint becomes more stringent $\left(\bar{\delta}_{H} \geq 60 \%\right.$, corresponding to a housing budget no greater than $40 \%$ of the household income), we observe the same phenomenon as in subsection 5.2.2: the mean and the range of the solvency level distribution decreases and increases, respectively. Again, this results from the eviction of low-income households from the city center toward suburban areas. Let us look at the case $\bar{\delta}_{H}=67 \%$, corresponding to the current $\mathrm{CH}$ constraint level in île-de-France. Relatively to the unconstrained case $\left(\bar{\delta}_{H}=0\right)$, low-income households are evicted from inner Paris (which is roughly a circle of radius $6 \mathrm{~km}$ ). They live in a suburban ring located between 10 and $23 \mathrm{~km}$ from the CBD (Figure 16), where they face higher transportation costs, hence the lower solvency levels. The model predicts rent levels around $22 € / \mathrm{m}^{2}$ in inner Paris, well matching the observed value of $21.7 €$ for 2008. ${ }^{29}$ The size of the Paris metropolitan area is slightly underestimated however, with a model prediction of only $40 \mathrm{~km}$, against $60 \mathrm{~km}$ according to Insee. The phenomenon of leap-frog development (Mills, 1981) - not included in our model - might account for the gap between predicted and observed values regarding city size. The monocentric model, despite its simplified representation of land use and transport, therefore seems to perform reasonably well in the case of the Paris region, justifying its use in first-line. ${ }^{30}$ Unlike $\mathrm{CH}$ policies, $\mathrm{CHT}$ prudential measures unequivocally improve the solvency of low-income households (be it the mean or range), as already observed in subsection 6.2.2 (Proposition 4). Again, this results from the key property of $\mathrm{CHT}$ constraints, being that they attract distant low-income households toward more central, accessible locations, and not the opposite as with $\mathrm{CH}$ constraints.

\footnotetext{
27 The authors compute the mean transport burden for a subdivision in 8 zones of the Greater Paris Region. Transport costs include fixed and variable costs for car users, purchase of passes and tickets for transit users, as well as potential benefits and tax reductions. A linear regression is performed on their results to produce the specification of $T(r)$ used in this application.

${ }^{28}$ Viguié et al. (2014) have successfully calibrated and applied a monocentric model to study energy transition scenarios for île-de-France, so that we can safely borrow most of their parameters. They use a slightly different boundary condition from usual, however: $R_{A}$ corresponds to the boundary housing rent level (i.e. the reservation housing rent below which real estate developers choose not to build) instead of the boundary land rent level. We use the same definition of $R_{A}$ in our application.

${ }^{29}$ Source: Clameur.

${ }^{30}$ Integrated land-use transport models (ITLUMs) could be used to yield more precise estimates of the effects of $\mathrm{CH}$ and CHT policies. The calibration and validation of ITLUMs still remains a challenge to this day, however, and the complexity of these models does not allow one to follow the economic mechanisms at work as we do here with the monocentric model.
} 
This point is illustrated in the case of île-de-France for $\bar{\delta}_{H T}=53 \%$ (which is the CHT equivalent level of the $\mathrm{CH}$ constraint $\bar{\delta}_{H}=67 \%$, in that they both lead to the same mean solvency level of 53\%). Here, low-income households are able to remain within the most central parts of the metropolitan area (Figure 16), but at the cost of higher housing prices than in the $\mathrm{CH}$ case (around $25 € / \mathrm{m}^{2}$ near the $\mathrm{CBD}$, against $22 € / \mathrm{m}^{2}$ in the $\mathrm{CH}$ case).

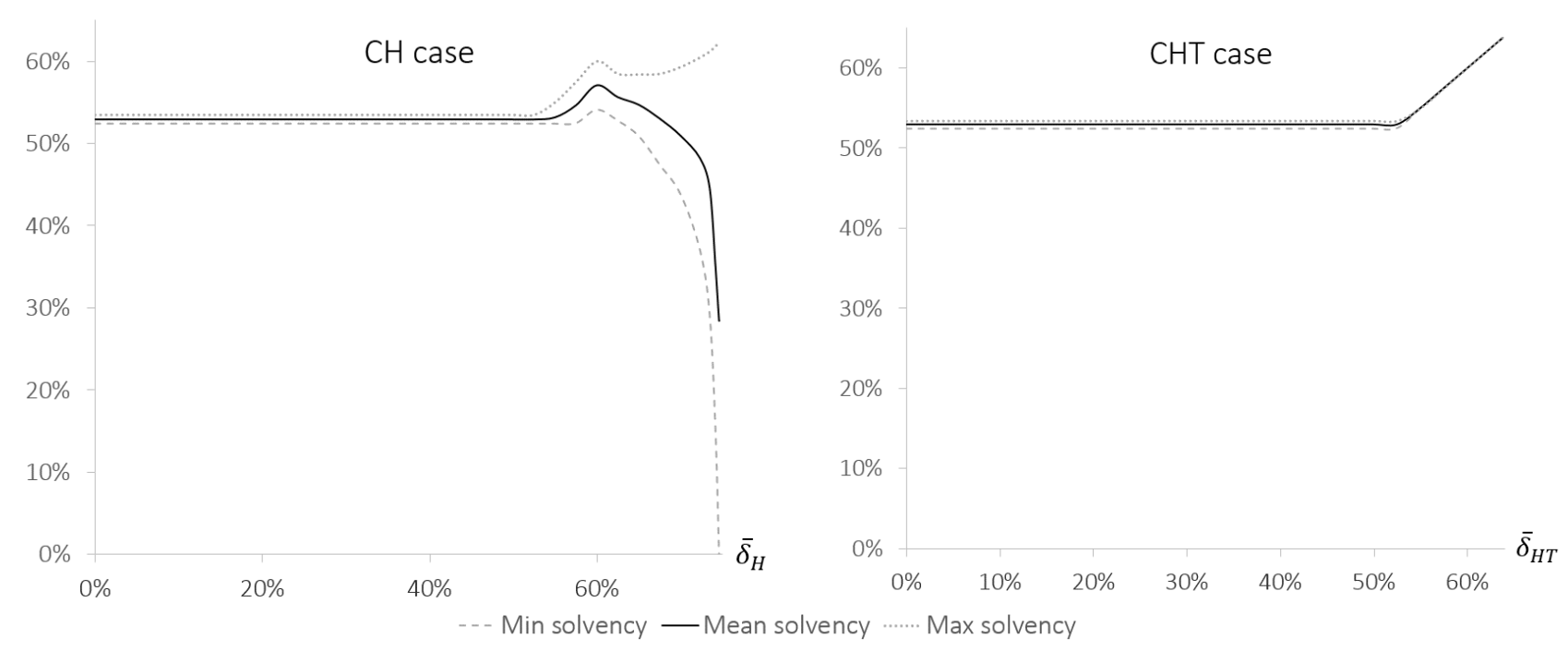

FIGURE 15: INFLUENCE OF CH AND CHT POLICIES ON THE SOLVENCY OF LOW-INCOME HOUSEHOLDS (PARIS REGION)

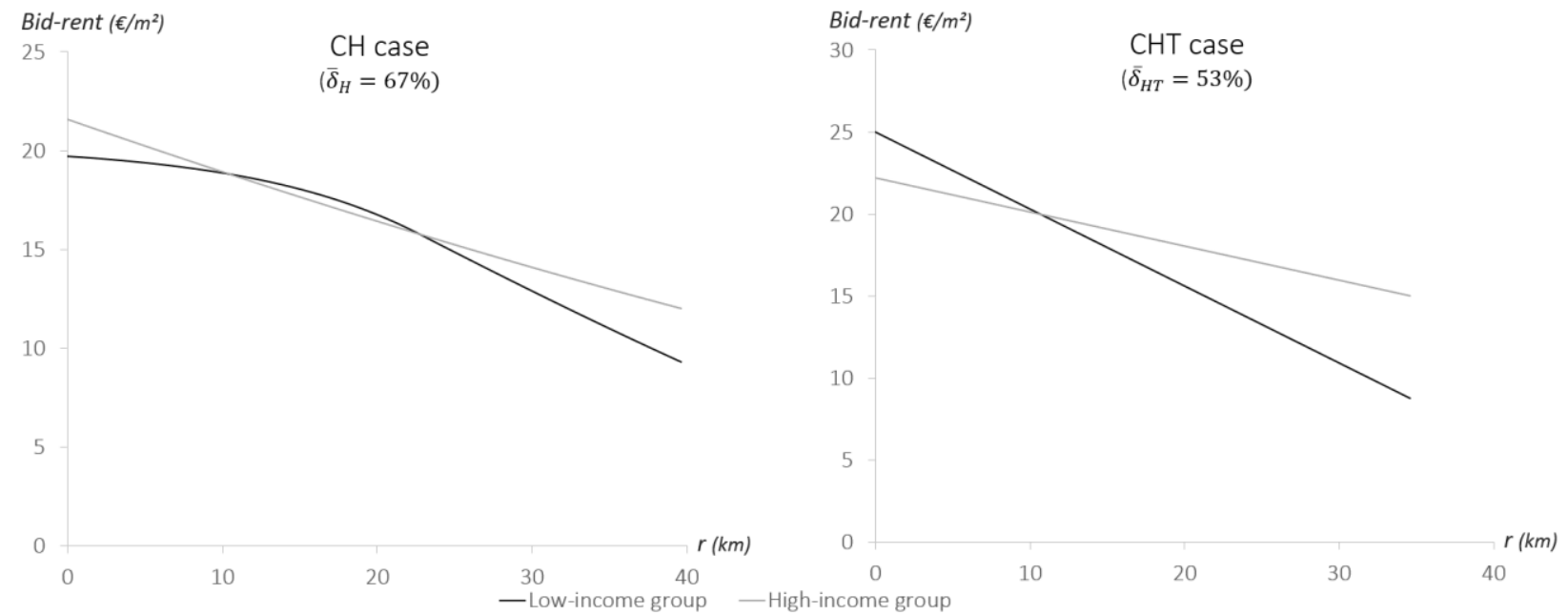

FIGURE 16: INFLUENCE OF CH AND CHT POLICIES ON BID RENTS AND INCOME SORTING (PARIS REGION)

Regarding household welfare, the effects of $\mathrm{CH}$ and $\mathrm{CHT}$ policies are similar to those previously observed with the linear city model (in subsections 5.2.1 and 6.2.1, respectively). High-income households benefit from the lower housing prices and thus experience higher equilibrium utility levels. Conversely, low-income households are more impacted in their choices by the $\mathrm{CH}$ and $\mathrm{CHT}$ constraints, and therefore tend to have lower equilibrium utility levels than in the unconstrained case (Figure A.1). For $\bar{\delta}_{H}=67 \%$, which corresponds to the current situation in the Paris region, the equilibrium utility 
of low-income households is 419.82 in the $\mathrm{CH}$ case, against 445.98 in the $\mathrm{CHT}$ case for $\bar{\delta}_{H T}=53 \%$. The CHT policy leads in this specific case to a better outcome for low-income households, both in terms of solvency and welfare, than the $\mathrm{CH}$ policy. Opting for a $\mathrm{CHT}$ policy would therefore be doubly beneficial in the case of Île-de-France.

\section{Discussion and conclusion}

\subsection{Discussion of the main findings}

The analysis of $\mathrm{CH}$ and $\mathrm{CHT}$ prudential measures has brought to light three main mechanisms:

- a direct solvency effect: by constraining the household budget allocation, $\mathrm{CH}$ and $\mathrm{CHT}$ policies mechanically improve the solvency of all households for a given level of housing prices;

- a relocation effect: $\mathrm{CH}$ policies have a centrifugal effect and encourage households, especially low-income ones, to move away from central, accessible locations and to settle in more distant areas with lower housing prices, but at the cost of high overall housing plus transport burdens. Conversely, CHT policies have a centripetal effect and incite households to settle in accessible neighborhoods, where housing plus transport burdens are low.

- an equilibrium effect: by limiting the households' bidding capacity and thus reducing the overall housing demand, both policies lead to a decrease in housing prices (through supply/demand adjustment mechanisms).

The direct and equilibrium effects both improve the solvency of all households (whatever their income). In the $\mathrm{CHT}$ case, the relocation effect also proves beneficial by encouraging locations with low overall housing plus transportation costs. As a result, the household solvency unequivocally improves when raising the $\mathrm{CHT}$ constraint level, be it regarding the mean or the range (Proposition 4). In the $\mathrm{CH}$ case, the relocation effect has a negative effect on low-income households, who are progressively compelled to move toward areas with low housing prices, but high overall housing plus transportation burdens. If the $\mathrm{CH}$ constraint is moderate, the direct and equilibrium effects are preponderant and household solvency improves. If the $\mathrm{CH}$ constraint is too strong, the relocation effect prevails and the solvency of low-income households worsens (Conjecture 1). ${ }^{31}$ In the case of the Paris region, we find that the current $\mathrm{CH}$ rule that caps the housing burden at $33 \%$ does indeed evict low-income households from the most central parts of the metropolitan area. Replacing it with a $\mathrm{CHT}$ rule of equivalent stringency (which would cap the housing plus transport burden at 47\%) would allow low-income households to settle in more central locations with lower transport costs, thereby greatly improving their solvency.

\footnotetext{
${ }^{31}$ In this section we only discuss the case $s_{0}>0$. If $s_{0}=0$, the centrifugal effect still exists but is much weaker. The direct and equilibrium effects prevail and the solvency of low-income households always increases.
} 
Additionally, the relocation effect of $\mathrm{CH}$ policies limits the efficiency of cost-cutting travel strategies (ride-sharing, car-sharing...), as illustrated in subsection 7.2. Last, CHT policies better protect lowincome households from fuel price spikes (subsection 7.1).

Regarding household welfare, the direct effect of $\mathrm{CH}$ and $\mathrm{CHT}$ prudential measures tends to lower the equilibrium utility (by constraining households to make sub-optimal choices), while the equilibrium effect raises utility by way of lower housing prices..$^{32}$ Provided that the constraint is not too stringent, the welfare of households, firstly of high-income ones (who are less impacted by the direct effect), improves as a result. Quite intuitively, the bearish effect on housing prices is stronger in the $\mathrm{CH}$ case (as the constraint bears directly on housing demand), so that households, again firstly high-income ones, are typically better off than under the CHT constraint. In the case of île-de-France, a policy change from the current $\mathrm{CH}$ rule (at $33 \%$ ) to a $\mathrm{CHT}$ rule (at $47 \%$ ) would - in addition to improving their solvency also actually improve the utility of low-income households. High-income households would experience a utility loss, however, as expected.

All in all, CHT prudential measures are efficient to protect the solvency of low-income households, whereas $\mathrm{CH}$ measures are less efficient in this regard, but improve the welfare of all income categories (as long as the constraint remains moderate). Because the primary purpose of prudential measures is to improve the solvency of households, not their welfare (which is the role of redistributive policies), $\mathrm{CHT}$ prudential measures should be preferred to $\mathrm{CH}$ rules. Furthermore, $\mathrm{CHT}$ measures do not lead to the eviction of low-income households from the central (or accessible) areas of the metropolitan area, which is another strong undesirable property of $\mathrm{CH}$ regulations.

Our findings are subject to a certain number of caveats. First, a strong assumption in the standard monocentric model is that location choices and housing prices are entirely driven by transport costs. One consequence of this assumption is that the model predicts that low-income households live near the $\mathrm{CBD}$ and high-income households in the suburbs. This prediction, though in line with empirical observations in the case of several US metropolitan areas, is in contradiction with the prevalence of affluent households in Paris. To account for this specificity, Brueckner et al. (1999) bring to light the role of amenities, which abound in inner Paris but are scarcer as one moves toward the periphery. While amenities are not considered in this paper, ${ }^{33}$ doing so would only strengthen our findings by adding another centrifugal force for low-income households. In the same line, our analysis has focused on the monetary costs of travel, in consistency with the design of $\mathrm{CH}$ and $\mathrm{CHT}$ prudential measures

\footnotetext{
${ }^{32}$ The relocation effect only affects the relative locations of low- and high-income households, with no effect on the equilibrium utility level.

${ }^{33}$ See Lemoy et al. (2010) for an operational monocentric model with amenities and several income classes.
} 
(which only consider monetary costs). Non-monetary dimensions of travel, firstly travel time, were not included in our model. Inasmuch as low-income households have lower values of travel time savings than high-income households, taking travel time into account would introduce yet another centrifugal force for low-income households, and therefore not change our main findings.

Second, we have considered only two income classes to keep the model simple. Our findings may easily generalize to a continuous income distribution, in which case the effects would progressively increase with distance to the median income. For instance, in the $\mathrm{CH}$ case the eviction effect would affect the poorest households first, then more and more households (raising the income ladder) as the constraint level increases.

Third, social housing is not represented in our model, whereas it is actually part of the solution. Indeed, in addition to providing low-income households with affordable housing, it is often located in dense, urban areas, with accessible public transit and transport costs that remain relatively low in comparison to more suburban or rural areas. Social housing therefore represents a straightforward and powerful means to keep low-income households within central, accessible neighborhoods. Because social housing is little, if at all, affected by market conditions, we could extend our model by considering an exogenous supply of social housing. By doing so, social housing would act as a buffer against the eviction effect of $\mathrm{CH}$ policies; otherwise, our main conclusions would remain unaltered.

\subsection{Policy recommendations}

Standard economic theory states regulation is needed only in presence of market inefficiencies, and is otherwise counterproductive. Based on the literature review and on our findings, we believe housing markets are indeed subject to a certain number of inefficiencies, which $\mathrm{CHT}$ prudential measures may address to some extent. First, households do not fully understand (or correctly appraise) the risk of default, and are therefore willing to accept excessive financial burdens (Hanna et al., 2012). This is likely to be even truer regarding the housing choice, inasmuch as households may be tempted to cross their financial limits to fulfill their social and environmental aspirations (Meissonnier, 2014). Furthermore, several works find that households are not perfectly informed of transportation costs; in particular, they tend to strongly underestimate the full cost of private cars (Meissonnier, 2014; Montagnon and Ringenbach, 2013; Rocci, 2007). Indeed, while information on housing prices is largely available ahead of (through real estate websites) and of course during the residential choice process, this is yet to be the case for transportation costs. ${ }^{34}$ Third, given the complexity of fuel price dynamics,

\footnotetext{
${ }^{34}$ While information on travel times is now easily available in most metropolitan areas through trip calculators (e.g. Google Maps), information on monetary costs remains seldom and partial at best.
} 
there is reason to believe fuel price volatility is largely misunderstood and poorly taken into account. Considering all these points, our findings support first using prudential measures in housing access, and second integrating transport costs within prudential ratios, and more generally speaking within indicators of housing affordability (especially when they are intended to assist households in their location decision-making process). In addition to protecting the solvency of low-income households, in particular from fuel price spikes, doing so would incidentally raise public awareness with regard to transport costs in general, the (high) full cost of private cars, and the issue of fuel price volatility. According to Chatman and Voorhoeve (2010), the raising awareness effect of CHT prudential measures would even likely be the primary benefit of such measures.

This leads to the question of the operational feasibility of prudential measures in general, and of CHT policies more specifically. As presented in Section 2, CH prudential measures are already applied in a number of countries, including the US and France. To do so, information relative to the household financial situation - including income - is typically collected from the household itself (information relative to housing costs being de facto always readily available to the lender or the landlord). Similarly, the concept of $\mathrm{CHT}$ prudential measures has already been operationalized in the US under the name of Location-Efficient Mortgages and Smart-Commute Mortgages, to which Chatman and Voorhoeve (2010) collectively refer as Transportation-Credit Mortgages (TCM). The TCM actually slightly differed from the original $\mathrm{CHT}$ concept: it raised the loan size for households willing to settle in accessible, transit-friendly areas. In other words, TCMs did not seek to directly assess the household's transport budget, but rather to capture the potential travel cost savings through the location accessibility. Relying on indirect indicators of the household's prospective transport burden, they only offered a limited amount of additional capital, being one of the reasons why they did not meet great success. ${ }^{35}$ Based on this previous experience, we believe $\mathrm{CHT}$ prudential measures should be implemented in the straightforward way, based on the direct assessment of the household's prospective transport costs. Doing so requires two things: 1) collecting all the necessary information to be able to estimate the future household's transport budget, and 2) having the appropriate tool to do the actual estimation. Regarding point 1), useful information includes by order of relevance: workplace(s) of household's members, number of cars, and ideally some information on the household's travel behavior (ridesharing, propensity to use public transit, frequency of commuting and non-commuting trips, ...). Workplace would in most cases be straightforwardly available to lenders or landlords, as they usually require information on the employer, job tenure, pay stubs... Information on the number of cars is partly available to lenders in case of car credit. Otherwise, it could be easily asked from households.

\footnotetext{
${ }^{35}$ See Chatman and Voorhoeve (2010) for an informative discussion on the US experience of TCMs.
} 
Regarding the household's travel behavior, collecting this information could be done in the case of lenders during one of the many appointments, but would likely be harder in the case of landlords. Relatively to point 2), transport budget calculators remain few and mostly stem from the academic community as for now. Among the existing initiatives, the Center for Neighborhood Technology has developed one such calculator in the US, while two tools, E-Mob and Mobicost (the latter as part of the MORECO European project), have already been developed in France.${ }^{36}$ In the absence of such tools, simple estimates could be derived by first estimating mode choice through the comparison of travel times by car, public transit, and active modes (which again is usually easily available through online trip calculators), then computing a tentative budget using a unit cost per kilometer in the case of car, the cost of the appropriate transit pass in the case of public transit... Let us stress that the objective of CHT prudential measures would not be to completely control the household's transport expenditures. Like for current $\mathrm{CH}$ prudential measures, one would verify that the $\mathrm{CHT}$ constraint is satisfied before the residential move, but following the residential move it would be really hard to track and control the household's travel behavior and the ensuing travel expenses. Rather, $\mathrm{CHT}$ prudential measures (like $\mathrm{CH}$ ones) would be intended as much as a way to limit the risk of insolvency that as a way to raise households' awareness to the risk of carrying excessive burdens. By putting forward this educational goal, information relative to travel behaviors could likely be collected more easily from households. Last, $\mathrm{CHT}$ initiatives could be profitably supported by transit authorities by providing temporary free transit passes to low-income households locating in transit-friendly areas thanks to these initiatives. This was experimented in the US as part of the TCM program, and was deemed very attractive by the households who enjoyed the free transit passes (Chatman and Voorhoeve, 2010).

\section{Acknowledgments}

This research was funded by the Fondation pour les Sciences Sociales, under the aegis of the Fondation de France. I would like to address my thanks to François Héran, its scientific head, to the laureates of the $2^{\text {ème }}$ Journée pour les Sciences Sociales, who greatly contributed to improving this work, and to Marjorie Raimond, who made this work possible. I would finally like to give my many thanks to the guest editors of the special issue, Giulio Mattioli, Carsten Gertz and Jean-Pierre Nicolas, as well as the two anonymous referees, for allowing me to submit to this special issue, and for their many comments and suggestions, which greatly helped in improving this work.

\footnotetext{
${ }^{36}$ See http://htaindex.cnt.org/ in the case of the US, and Crozy et al. (2016) for more information on the French initiatives.
} 


\section{References}

Alonso, W., 1964. Location and Land Use. Harvard University Press, Cambridge, MA.

Anas, A., Arnott, R., Small, K., 1998. Urban Spatial Structure. Journal of Economic Literature 36, 1426-1464.

Anas, A., Arnott, R.J., Small, K.A., 2000. The Panexponential Monocentric Model. Journal of Urban Economics 47, 165-179. doi:10.1006/juec.1999.2137

Anas, A., Moses, L.N., 1979. Mode choice, transport structure and urban land use. Journal of Urban Economics 6, 228-246. doi:10.1016/0094-1190(79)90007-X

Arnott, R.J., Stiglitz, J.E., 1981. Aggregate Land Rents and Aggregate Transport Costs. The Economic Journal 331347.

Berri, A., 2007. Residential Location and Household Expenditures on Transport and Housing: The Example of the Greater Paris Region. Presented at the 11th World Conference on Transport Research.

Berry, A., Jouffe, Y., Coulombel, N., Guivarch, C., 2016. Investigating fuel poverty in the transport sector: Toward a composite indicator of vulnerability. Energy Research \& Social Science. doi:10.1016/j.erss.2016.02.001

Bertaud, A., Brueckner, J.K., 2005. Analyzing building-height restrictions: predicted impacts and welfare costs. Regional Science and Urban Economics 35, 109-125. doi:10.1016/j.regsciurbeco.2004.02.004

Blackman, A., Krupnick, A., 2001. Location-Efficient Mortgages: Is the Rationale Sound? J. Pol. Anal. Manage. 20, 633-649. doi:10.1002/pam.1021

Breteau, V., Leurent, F., 2010. Housing and commuting in an extended monocentric model, Working Paper.

Brueckner, J.K., 2009. Government Land Use Interventions: An Economic Analysis, in: Lall, S.V., Freire, M., Yuen, B., Rajack, R., Helluin, J.-J. (Eds.), Urban Land Markets. Springer Netherlands, pp. 3-23.

Brueckner, J.K., 1979. A model of non-central production in a monocentric city. Journal of Urban Economics 6, 444-463. doi:10.1016/0094-1190(79)90024-X

Brueckner, J.K., Thisse, J.-F., Zenou, Y., 1999. Why is central Paris rich and downtown Detroit poor?: An amenitybased theory. European Economic Review 43, 91-107.

CGDD, SOeS, 2009. Le poids du logement dans le budget des ménages: une approche historique et générationnelle du taux d'effort (Compte du logement provisoire 2007).

Chatman, D., Voorhoeve, N., 2010. The transportation-credit mortgage: a post-mortem. Housing Policy Debate 20, 355-382. doi:10.1080/10511481003788786

Coulombel, Leurent, Deschamps, 2007. Residential choice and household strategies in the Greater Paris Region. Presented at the European Transport Conference.

Coulombel, N., 2016. Prudential measures in housing access: should one include transport costs in the front-end ratio? Journal of Transport and Land Use in press.

Coulombel, N., 2010. Toward a Better Representation of Housing Demand: On the role of monetary and nonmonetary costs in household residential strategies. Ecole des Ponts, Champs-sur-Marne, France.

Coulombel, N., Leurent, F., 2013. Les ménages arbitrent-ils entre coût du logement et coût du transport : une réponse dans le cas francilien. Economie et Statistique 457-458, 57-75.

Crozy, J., Coulombel, N., Jouffe, Y., Marquet, S., Nicolas, J.-P., 2016. Le coût résidentiel : de quoi parle-t-on?, Collection L'essentiel. CEREMA, Lyon, France.

Fisher, L.M., Pollakowski, H.O., Zabel, J., 2009. Amenity-Based Housing Affordability Indexes. Real Estate Economics 37, 705-746. doi:10.1111/j.1540-6229.2009.00261.x

Fujita, M., 1989. Urban Economic Theory: Land Use and City Size. Cambridge University Press.

Galtung, J., 1979. The Basic Needs Approach. University of Oslo.

Ghai, D., 1978. Basic Needs and its Critics. The IDS Bulletin 9, 16-18. doi:10.1111/j.1759-5436.1978.mp9004004.x Gobillon, L., 2008. Une Synthèse de la Littérature sur la Consommation de Logement des Ménages. 
Haas, P.M., Makarewicz, C., Benedict, A., Sanchez, T.W., Dawkins, C.J., 2006. Housing \& Transportation Cost Trade-Offs and Burdens of Working Households in 28 Metros. Center for Neighborhood Technology.

Hanna, S.D., Yuh, Y., Chatterjee, S., 2012. The increasing financial obligations burden of US households: who is affected? International Journal of Consumer Studies 36, 588-594. doi:10.1111/j.1470-6431.2012.01125.x

Hare, P.H., 1994. One-car mortgages and one-car rents. Land Development 12.

Hickey, R., Lubell, J., Haas, P., Morse, S., 2012. Losing Ground: The struggle of moderate-income households to afford the rising costs of housing and transportation. Washington, DC: Center for Housing Policy.

Holtzclaw, J., Clear, R., Dittmar, H., Goldstein, D., Haas, P., 2002. Location Efficiency: Neighborhood and SocioEconomic Characteristics Determine Auto Ownership and Use - Studies in Chicago, Los Angeles and San Francisco. Transportation Planning and Technology 25, 1-27. doi:10.1080/03081060290032033

Kaza, N., Riley, S.F., Quercia, R.G., Tian, C.Y., 2016. Location Efficiency and Mortgage Risks for Low-Income Households. Housing Policy Debate 26, 750-765. doi:10.1080/10511482.2016.1159972

Kilani, M., Leurent, F., de Palma, A., 2010. Monocentric City with Discrete Transit Stations. Transportation Research Record: Journal of the Transportation Research Board 2144, 36-43. doi:10.3141/2144-05

Kutty, N.K., 2005. A new measure of housing affordability: Estimates and analytical results. Housing Policy Debate 16, 113-142. doi:10.1080/10511482.2005.9521536

Legras, S., 2015. Correlated environmental impacts of wastewater management in a spatial context. Regional Science and Urban Economics 52, 83-92. doi:10.1016/j.regsciurbeco.2015.03.002

Lemoy, R., Raux, C., Jensen, P., 2010. An agent-based model of residential patterns and social structure in urban areas. Cybergeo : European Journal of Geography. doi:10.4000/cybergeo.23381

Meissonnier, J., 2014. Politiques énergétiques et accession à la propriété: le point de vue des familles.

Mills, D.E., 1981. Growth, speculation and sprawl in a monocentric city. Journal of Urban Economics 10, 201226. doi:10.1016/0094-1190(81)90015-2

Montagnon, M., Ringenbach, C., 2013. Crédit immobilier et résilience énergétique - Prise en compte des dépenses énergétiques dans les projets d'accession à la propriété.

Muth, R.F., 1969. Cities and Housing: The Spatial Pattern of Urban Residential Land Use. University of Chicago Press.

Nicolas, J.-P., Vanco, F., Verry, D., 2012. Mobilité quotidienne et vulnérabilité des ménages. Revue d’Économie Régionale \& Urbaine février, 19-44.

Ogawa, H., Fujita, M., 1980. Equilibrium Land Use Patterns in a Nonmonocentric City. Journal of Regional Science 20, 455-475. doi:10.1111/j.1467-9787.1980.tb00662.x

Pivo, G., 2014. Walk Score: The Significance of 8 and 80 for Mortgage Default Risk in Multifamily Properties. Journal of Sustainable Real Estate 6, 187-210. doi:10.5555/jsre.6.2.a065835258712250

Polacchini, A., Orfeuil, J.-P., 1999. Les dépenses des ménages franciliens pour le logement et les transports. Recherche - Transports - Sécurité 63, 31-46. doi:10.1016/S0761-8980(00)80039-4

Rauterkus, S., Thrall, G., Hangen, E., 2010. Location Efficiency and Mortgage Default. Journal of Sustainable Real Estate 2, 117-141. doi:10.5555/jsre.2.1.w00u2v11w56118p7

Renne, J.L., Sturtevant, L.A., 2016. Background, Outline, Emerging Themes, and Implications for Housing and Transportation Policy. Housing Policy Debate 26, 563-567. doi:10.1080/10511482.2016.1199639

Revington, N., Townsend, C., 2016. Market Rental Housing Affordability and Rapid Transit Catchments: Application of a New Measure in Canada. Housing Policy Debate 26, 864-886. doi:10.1080/10511482.2015.1096805

Rocci, A., 2007. De l'automobilité à la multimodalité? Analyse sociologique des freins et leviers au changement de comportements vers une réduction de l'usage de la voiture. Le cas de la région parisienne et perspective internationale. (phdthesis). Université René Descartes - Paris V. 
Schwarz, M., Wilson, E., 2008. Who Can Afford To Live in a Home?: A look at data from the 2006 American Community Survey. U.S. Census Bureau.

Stone, M.E., 2006. What is housing affordability? The case for the residual income approach. Housing Policy Debate 17, 151-184. doi:10.1080/10511482.2006.9521564

Thünen, J.H. von, 1826. Der isolierte Staat in Beziehung auf Landwirtschaft und Nationalökonomie. Friedrich Perthes, Hamburg.

Turner, M.A., Haughwout, A., van der Klaauw, W., 2014. Land Use Regulation and Welfare. Econometrica 82, 1341-1403. doi:10.3982/ECTA9823

Viguié, V., Hallegatte, S., Rozenberg, J., 2014. Downscaling long term socio-economic scenarios at city scale: A case study on Paris. Technological Forecasting and Social Change 87, 305-324. doi:10.1016/j.techfore.2013.12.028

White, M.J., 1988. Location choice and commuting behavior in cities with decentralized employment. Journal of Urban Economics 24, 129-152. doi:10.1016/0094-1190(88)90035-6

Yinger, J., 1992. City and suburb: Urban models with more than one employment center. Journal of Urban Economics 31, 181-205. doi:10.1016/0094-1190(92)90052-M 


\section{Appendix A - Proofs}

\section{Proofs for Section 2}

\section{$\underline{\text { Bid-max variables }}$}

The Lagrangian corresponding to the bid-max problem (2) is:

$$
\mathcal{L}=\frac{Y-T(r)-z}{s}+\lambda\left(\left(s-s_{0}\right)^{\alpha}\left(z-z_{0}\right)^{1-\alpha}-u\right)
$$

First-order optimality conditions (FOC) are:

$$
\left\{\begin{array}{c}
-\frac{1}{s}+\lambda(1-\alpha)\left(s-s_{0}\right)^{\alpha}\left(z-z_{0}\right)^{-\alpha}=0 \\
-\frac{Y-T(r)-z}{s^{2}}+\lambda \alpha\left(s-s_{0}\right)^{\alpha-1}\left(z-z_{0}\right)^{1-\alpha}=0 .
\end{array}\right.
$$

Combining the two FOC yields: $\left(z-z_{0}\right) /(1-\alpha)=\Psi(r, u)\left(s-s_{0}\right) / \alpha$. Using the household budget constraint, we get:

$$
\left\{\begin{array}{l}
s(r, u)=s_{0}+\alpha \frac{\left(Y-z_{0}-a r-\Psi(r, u) s_{0}\right)}{\Psi(r, u)}, \\
z(r, u)=z_{0}+(1-\alpha)\left(Y-z_{0}-a r-\Psi(r, u) s_{0}\right) .
\end{array}\right.
$$

Substituting (16) in the bid-max constraint $\left(s-s_{0}\right)^{\alpha}\left(z-z_{0}\right)^{1-\alpha}=u$ provides the last relationship:

$$
u \Psi(r, u)^{\alpha}+A s_{0} \Psi(r, u)=\mathrm{A}\left(Y-z_{0}-a r\right),
$$

with $A=\alpha^{\alpha}(1-\alpha)^{1-\alpha}$.

\section{Proof of Lemma 1}

The derivative of the housing burden is $\tau_{H}{ }^{\prime}(r)=\left((1-\alpha) R^{\prime}(r) s_{0}-\alpha a\right) / Y$. Given that $R^{\prime}(r)<0$, we have $\tau_{H}{ }^{\prime}(r)<0$. For the housing plus transport burden, we have $\tau_{H T}{ }^{\prime}(r)=-\tau_{z}{ }^{\prime}(r)>0$ according to the properties of $z(r, u)$ stated above.

\section{Proof of Lemma 2}

The joint HT burden $\tau_{H T}(r)$ is a linear function of $1 / Y$ with coefficient $(1-\alpha)\left(R(r) s_{0}+a r\right)-\alpha z_{0}$. As $\forall r \in \mathbb{R}^{+}, R(r) \geq R_{A}$, we have $(1-\alpha)\left(R(r) s_{0}+a r\right)-\alpha z_{0} \geq(1-\alpha) R_{A} s_{0}-\alpha z_{0} \geq 0$ based on the assumption from 3.3. This shows that $\tau_{H T}(r)$ decreases with $Y$ for all $r \in \mathbb{R}^{+}$.

The housing expense ratio is also an hyperbola in $Y$, but its coefficient $(1-\alpha) R(r) s_{0}-\alpha z_{0}-\alpha a r$ switches sign for $r \geq r_{H}$, where $r_{H}$ is implicitly defined by $(1-\alpha) R\left(r_{H}\right) s_{0}=\alpha\left(z_{0}+a r_{H}\right)$. As a result, the housing burden decreases with $Y$ if $r \leq r_{H}$, but increases for $r \geq r_{H}$. In the limiting case $s_{0}=0$, the threshold $r_{H}=0$, and the housing burden always increases with income, whatever the location. 


\section{Proofs for Section 3}

\section{Proof of Lemma 3}

The constrained zone is the set of locations where the unconstrained housing expense ratio exceeds the authorized limit: $\left\{r \in \mathbb{R}^{+} / \tau_{H}(r) \geq \delta_{H}\right\}$. It is the preimage of $\left[\delta_{H}, 1\right]$ under the function $\tau_{H}($.$) .$ Because $\tau_{H}(r)$ decreases with $r$ (Lemma 1 ), the constrained zone has the form $\left\{r \in \mathbb{R}^{+} / r \leq \hat{r}_{c}\left(\delta_{H}\right)\right\}$, where $\hat{r}_{c}\left(\delta_{H}\right)$ decreases with $\delta_{H}$. Using $\bar{\delta}_{H}=1-\delta_{H}$, this means that $\hat{r}_{c}\left(\bar{\delta}_{H}\right)$ increases with $\bar{\delta}_{H}$.

Assume $s_{0}=0$. The unconstrained housing burden $\tau_{H}(r)$ increases with $Y$ at all locations (Lemma 2). This implies that $\hat{r}_{c}\left(\bar{\delta}_{H}\right)$ also increases with $Y$.

\section{$\underline{\text { Proposition } 1 \text { and Conjecture } 1}$}

We first prove Proposition 1, then sketch the proof of Conjecture 1.

Assume $s_{0}=0$. Following Fujita (1989), the income sorting order depends on the relative steepness of the bid rent functions of the two income classes. Let $\hat{r}_{P / R}$ be one of the possibly many frontier points between these two classes. At $\hat{r}_{P / R}$, there are three alternatives: A) no income group is constrained, B) the low-income group is constrained, and C) both income groups are constrained. Given Lemma 3, the last possibility where the high-income class is constrained but not the low-income one never arises. We are going to show that $\left|\widehat{\Psi}_{r}^{R}\left(\hat{r}_{P / R}, \hat{u}_{e}^{R}\right)\right|<\left|\widehat{\Psi}_{r}^{P}\left(\hat{r}_{P / R}, \hat{u}_{e}^{P}\right)\right|$ in all three alternatives.

Case A corresponds to the unconstrained situation, with $\left|\widehat{\Psi}_{r}^{P}\left(\hat{r}_{P / R}, \hat{u}_{e}^{P}\right)\right|=\left|\Psi_{r}^{P}\left(\hat{r}_{P / R}, \hat{u}_{e}^{P}\right)\right|$ and $\left|\widehat{\Psi}_{r}^{R}\left(\hat{r}_{P / R}, \hat{u}_{e}^{R}\right)\right|=\left|\Psi_{r}^{R}\left(\hat{r}_{P / R}, \hat{u}_{e}^{R}\right)\right|$, in which case $\left|\Psi_{r}^{R}\right|<\left|\Psi_{r}^{P}\right|$ is a well-known property (Fujita, 1989).

In case $\mathrm{B}$, the high-income class is unconstrained: $\left|\widehat{\Psi}_{r}^{R}\right|=\left|\Psi_{r}^{R}\right|=a / \widehat{\mathrm{s}}^{R}$. Because of the Stone-Geary utility function, we have $R\left(\hat{r}_{P / R}\right) \hat{\mathrm{s}}^{R} / \alpha=\left(\hat{z}^{R}-z_{0}\right) /(1-\alpha)$ hence $\left|\widehat{\Psi}_{r}^{R}\right|=\frac{1-\alpha}{\alpha} a R\left(\hat{r}_{P / R}\right) /\left(\hat{z}^{R}-z_{0}\right)$. Regarding the low-income class, which is constrained, we have $\left|\widehat{\Psi}_{r}^{P}\right|=\frac{1-\alpha}{\alpha} a \delta_{H} Y^{P} /\left(\hat{\mathrm{s}}^{P} *\left(\hat{z}^{P}-z_{0}\right)\right)$ from (12). We also have $R\left(\hat{r}_{P / R}\right) \widehat{\mathrm{S}}^{P}=\delta_{H} Y^{P}$, entailing $\left|\widehat{\Psi}_{r}^{P}\right|=\frac{1-\alpha}{\alpha} a R\left(\hat{r}_{P / R}\right) /\left(\hat{z}^{P}-z_{0}\right)$. All in all, $\left|\widehat{\Psi}_{r}^{P}\right|>\left|\widehat{\Psi}_{r}^{R}\right| \Leftrightarrow \hat{z}^{P}<\hat{z}^{R}$. The low-income class is constrained hence $\hat{z}^{P}=\bar{\delta}_{H} Y^{P}-a \hat{r}_{P / R}$, while the high-income class is not meaning that $\hat{z}^{R}>\bar{\delta}_{H} Y^{R}-a \hat{r}_{P / R}>\bar{\delta}_{H} Y^{P}-a \hat{r}_{P / R}=\hat{z}^{P}$.

In case $\mathrm{C}$, both income groups are constrained. Again, we have $\left|\widehat{\Psi}_{r}^{P}\right|=\frac{1-\alpha}{\alpha} a R\left(\hat{r}_{P / R}\right) /\left(\hat{z}^{P}-z_{0}\right)$ and $\left|\widehat{\Psi}_{r}^{R}\right|=\frac{1-\alpha}{\alpha} a R\left(\hat{r}_{P / R}\right) /\left(\hat{z}^{R}-z_{0}\right)$ from (12), hence the equivalence $\left|\widehat{\Psi}_{r}^{P}\right|>\left|\widehat{\Psi}_{r}^{R}\right| \Leftrightarrow \hat{z}^{P}<\hat{z}^{R}$. Because the two income groups are constrained, we have $\hat{z}^{R}=\bar{\delta}_{H} Y^{R}-a \hat{r}_{P / R}>\bar{\delta}_{H} Y^{P}-a \hat{r}_{P / R}=\hat{z}^{P}$, which concludes the proof of Proposition 1. 
Now assume $s_{0}>0$. As discussed in 5.1.1, the unconstrained housing burden $\tau_{H}(r)$ decreases with $Y$ near the CBD but increases with $Y$ beyond. Contrary to the case $s_{0}=0$, low-income households are more impacted than high-income ones near the CBD.

In case $\mathrm{A}$, the two income groups are unconstrained. As previously, $\left|\widehat{\Psi}_{r}^{P}\right|=\left|\Psi_{r}^{P}\right|>\left|\Psi_{r}^{R}\right|=\left|\widehat{\Psi}_{r}^{R}\right|$. When the $\mathrm{CH}$ constraint is weak, the relative location of the two income groups remains unchanged.

Things do change in case $\mathrm{B}$, however. For the high-income group, we still have $\left|\widehat{\Psi}_{r}^{R}\right|=\left|\Psi_{r}^{R}\right|=a / \widehat{\mathrm{s}}^{R}$. Because $s_{0}>0$, the Stone-Geary property writes $R\left(\hat{r}_{P / R}\right)\left(\hat{\mathrm{s}}^{R}-s_{0}\right) / \alpha=\left(\hat{z}^{R}-z_{0}\right) /(1-\alpha)$, yielding $\left|\widehat{\Psi}_{r}^{R}\right|=\frac{1-\alpha}{\alpha} a R\left(\hat{r}_{P / R}\right)\left(\hat{\mathrm{s}}^{R}-s_{0}\right) / \hat{\mathrm{s}}^{R} * 1 /\left(\hat{z}^{R}-z_{0}\right)$. Regarding the low-income class, we now have $\left|\widehat{\Psi}_{r}^{P}\right|=\frac{1-\alpha}{\alpha} a \delta_{H} Y^{P}\left(\hat{\mathrm{s}}^{P}-s_{0}\right) /\left(\hat{\mathrm{s}}^{P}\right)^{2} * 1 /\left(\hat{z}^{P}-z_{0}\right)$. Using the $\mathrm{CH}$ constraint $R\left(\hat{r}_{P / R}\right) \widehat{\mathrm{s}}^{P}=\delta_{H} Y^{P}$ yields $\left|\widehat{\Psi}_{r}^{P}\right|=\frac{1-\alpha}{\alpha} a R\left(\hat{r}_{P / R}\right)\left(\hat{\mathrm{s}}^{P}-s_{0}\right) / \hat{\mathrm{s}}^{P} * 1 /\left(\hat{z}^{P}-z_{0}\right)$. The relative steepness of the two bid rent functions is therefore given by the following condition:

$$
\left|\widehat{\Psi}_{r}^{P}\right| \gtreqless\left|\widehat{\Psi}_{r}^{R}\right| \Leftrightarrow\left(\hat{z}^{P}-z_{0}\right) * \frac{\hat{\mathrm{s}}^{P}}{\hat{\mathrm{S}}^{P}-s_{0}} \lesseqgtr\left(\hat{z}^{R}-z_{0}\right) * \frac{\hat{\mathrm{s}}^{R}}{\hat{\mathrm{S}}^{R}-s_{0}} .
$$

Although we still have $\hat{z}^{P}-z_{0}<\hat{z}^{R}-z_{0}$, regarding the second factor we have $\hat{\mathrm{s}}^{P}<\hat{\mathrm{s}}^{R} \Rightarrow$ $\hat{\mathrm{s}}^{P} /\left(\hat{\mathrm{s}}^{P}-s_{0}\right)>\widehat{\mathrm{s}}^{R} /\left(\hat{\mathrm{s}}^{R}-s_{0}\right)$. Thus, the order relationship between $\left|\widehat{\Psi}_{r}^{P}\right|$ and $\left|\widehat{\Psi}_{r}^{R}\right|$ is undetermined. As the $\mathrm{CH}$ constraint level increases and $\hat{\mathrm{s}}^{P}$ tends toward $s_{0}$, the term $\hat{\mathrm{s}}^{P} /\left(\hat{\mathrm{s}}^{P}-s_{0}\right)$ tends toward $+\infty$, which leads $\left|\widehat{\Psi}_{r}^{P}\right|<\left|\widehat{\Psi}_{r}^{R}\right|$. This implies that as $\bar{\delta}_{H}$ increases the relative steepness of the two bid rent functions should switch at some point, causing low-income households to be evicted from the city center. Although we could not establish this point formerly (in particular because the analytical derivation of the equilibrium utility in the $\mathrm{CH}$ monocentric model with two income classes could not be achieved), this is indeed what we observe numerically, hence Conjecture 1.

\section{Proofs for the CHT monocentric model}

\section{Proof of Lemma 4}

The constrained zone is the set of locations where the unconstrained housing plus transport expense ratio exceeds the authorized limit: $\left\{r \in \mathbb{R}^{+} / \tau_{H T}(r) \geq \delta_{H T}\right\}$. Equivalently, it is the preimage of $\left[\delta_{H T}, 1\right]$ under the function $\tau_{H T}($.$) . Because \tau_{H T}(r)$ increases with $r$ (Lemma 1 ), the constrained zone has the form $\left\{r \in \mathbb{R}^{+} / r \geq r_{c}^{i}\left(\delta_{H T}\right)\right\}$, where $r_{c}^{i}\left(\delta_{H T}\right)$ increases with $\delta_{H T}$. Using $\bar{\delta}_{H T}=1-\delta_{H T}$, this means that $r_{c}^{i}\left(\bar{\delta}_{H T}\right)$ decreases with $\bar{\delta}_{H T}$. Similarly, $\tau_{H T}(r)$ decreases with income (Lemma 2), which implies that $r_{c}^{i}\left(\bar{\delta}_{H T}\right)$ increases with $Y$. 


\section{Proof of Proposition 2}

Following Fujita (1989), the income sorting order depends on the relative steepness of the bid rent functions of the two income classes. Let $\tilde{r}_{P / R}$ be one of the possibly many frontier points between the two income classes. At $r_{P / R}$, we have:

$$
\widetilde{\Psi}_{r}^{h}\left(\tilde{r}_{P / R}, \tilde{u}_{e}^{h}\right)=-\frac{a}{\tilde{s}^{h}\left(\tilde{r}_{P / R}, \tilde{u}_{e}^{h}\right)} \forall h \in\{P, R\}
$$

If $\tilde{s}^{P}\left(\tilde{r}_{P / R}, \tilde{u}_{e}^{P}\right)<\tilde{s}^{R}\left(\tilde{r}_{P / R}, \tilde{u}_{e}^{R}\right)$ the bid rent function of the low-income class is steeper than that of the high income class, and vice versa. There are three possibilities: A) no income class is constrained, B) the low-income class is constrained, and C) both income classes are constrained. Given Lemma 2, the last possibility where the high-income class is constrained but not the low-income one never arises. We are now going to show that $\tilde{s}^{P}<\tilde{s}^{R}$ in all three alternatives (the $r$ and $u$ arguments being omitted for concision), meaning that the bid rent function of low-income households is always steeper than that of high-income households, which will conclude the proof.

Case A corresponds to the unconstrained situation, with $\tilde{s}^{P}=s^{P}$ and $\tilde{s}^{R}=\mathrm{s}^{R}$. In this case, the inequality $s^{P}<\mathrm{s}^{R}$ stems from the assumption that land is a normal good (Fujita, 1989).

In case $\mathrm{B}$, we have $\tilde{s}^{P}<s^{P}$ (from (15)) and $\tilde{s}^{R}=\mathrm{s}^{R}$, hence $\tilde{s}^{P}<\tilde{s}^{R}$ using again $s^{P}<\mathrm{s}^{R}$.

In case $\mathrm{C}$, both income classes are constrained, hence $\forall h \in\{P, R\}, R\left(\tilde{r}_{P / R}\right) \tilde{s}^{h}+a \tilde{r}_{P / R}=\delta_{H T} Y^{h}$. This implies $\tilde{s}^{h}=\left(\delta_{H T} Y^{h}-a \tilde{r}_{P / R}\right) / R\left(\tilde{r}_{P / R}\right)$. Because $Y^{P}<Y^{R}, \tilde{s}^{P}<\tilde{s}^{R}$ is straightforward.

\section{Proof of Proposition 3}

There are three different regimes depending on the level of the $\mathrm{CHT}$ constraint. During the first regime $\left(0 \leq \bar{\delta}_{H T} \leq \bar{\delta}_{H T}^{0}\right)$, the $\mathrm{CHT}$ constraint is ineffective: none of the low-income households is constrained. We are in the unconstrained situation, hence:

$$
\left\{\begin{array}{l}
\tilde{u}_{e}^{P}\left(\bar{\delta}_{H T}\right)=A \frac{Y^{P}-z_{0}-\left(R_{A}+a N\right) s_{0}}{\left(R_{A}+a N\right)^{\alpha}} \\
\tilde{r}_{P / R}\left(\bar{\delta}_{H T}\right)=\frac{1}{a}\left(\left(1-K^{\alpha}\right)\left(Y^{P}-z_{0}\right)+\left(K^{\alpha}-K\right)\left(R_{A}+a N\right) s_{0}\right)
\end{array},\right.
$$

with $\left.K=\frac{R_{A}+a N^{R}}{R_{A}+a N} \in\right] 0 ; 1\left[\right.$. The equilibrium utility level $\tilde{u}_{e}^{P}\left(\bar{\delta}_{H T}\right)$ of the low-income group and the size $\tilde{r}_{P / R}\left(\bar{\delta}_{H T}\right)$ of its residential area are both independent of $\bar{\delta}_{H T}$, and thereby constant. The first regime ends when the household living at the border $\tilde{r}_{P / R}$ becomes constrained. This occurs when:

$$
\begin{gathered}
z\left(\tilde{r}_{P / R}, \tilde{u}_{e}^{P}\right)=z_{0}+K^{\alpha}(1-\alpha)\left(Y^{P}-z_{0}-\left(R_{A}+a N\right) s_{0}\right)=\bar{\delta}_{H T}^{0} Y^{P}, \\
\Leftrightarrow \bar{\delta}_{H T}^{0}=K^{\alpha}(1-\alpha)-\frac{K^{\alpha}(1-\alpha)\left(z_{0}+\left(R_{A}+a N\right) s_{0}\right)-z_{0}}{Y^{P}} .
\end{gathered}
$$


In the second regime (with $\bar{\delta}_{H T}^{0} \leq \bar{\delta}_{H T} \leq \bar{\delta}_{H T}^{1}$ ), the $\mathrm{CHT}$ constraint is stronger and starts to be effective: the most remote low-income households are affected, whereas those living near the CBD are not (yet). For the household living at $r=0$, the market conditions remain the same as in the unconstrained case, meaning that the equilibrium utility level does not change, with $\tilde{u}_{e}^{P}\left(\bar{\delta}_{H T}\right)=A \frac{Y^{P}-z_{0}-\left(R_{A}+a N\right) s_{0}}{\left(R_{A}+a N\right)^{\alpha}}$. As the most remote households are constrained, the size of the low-income area starts to decrease, however. Using $R\left(\tilde{r}_{P / R}\right)=R_{A}+a N^{R}$ and $\tau_{H T}^{P}\left(\tilde{r}_{P / R}\right)=\delta_{H T}$, the limit of the low-income ring is now given by:

$$
\tilde{r}_{P / R}\left(\bar{\delta}_{H T}\right)=\frac{1}{a}\left(\delta_{H T} Y^{P}-\left(R_{A}+a N^{R}\right)\left(s_{0}+\tilde{u}_{e}^{P \frac{1}{\alpha}}\left(\bar{\delta}_{H T} Y^{P}-z_{0}\right)^{\frac{\alpha-1}{\alpha}}\right)\right) .
$$

To show that when the CHT constraint becomes stronger (i.e. $\bar{\delta}_{H T}$ decreases), $\tilde{r}_{P / R}\left(\bar{\delta}_{H T}\right)$ decreases, rather than deriving the previous relationship, which proves quite tedious, we use a simple argument. In the second regime, when $\bar{\delta}_{H T}$ increases, because utility remains constant, lot size decreases at all constrained locations (from (15)). Given the population constraint $\int_{0}^{\tilde{r}_{P / R}} 1 / \widetilde{\mathrm{s}}^{P}\left(r, \tilde{u}_{e}^{P}\right) d r=N^{P}$ for the low-income group, the fact that $\widetilde{\mathrm{s}}^{P}\left(r, \tilde{u}_{e}^{P}\right)$ decreases at all constrained locations implies that $\tilde{r}_{P / R}\left(\bar{\delta}_{H T}\right)$ strictly decreases. The second regime ends when the household living at the CBD becomes constrained, which occurs when:

$$
z\left(0, \tilde{u}_{e}^{P}\right)=\bar{\delta}_{H T}^{1} Y^{P} \Leftrightarrow \bar{\delta}_{H T}^{1}=1-\alpha-\left((1-\alpha)\left(R_{A}+a N\right) s_{0}-\alpha z_{0}\right) / Y^{P} .
$$

In the last regime (with $\bar{\delta}_{H T}>\bar{\delta}_{H T}^{1}$ ), all households are constrained. Again, we first consider the household living at the CBD. Using (15) and $R(0)=R_{A}+a N$, we have :

$$
\tilde{u}_{e}^{P}\left(\bar{\delta}_{H T}\right)=\left(\frac{\delta_{H T} Y^{P}}{R_{A}+a N}-s_{0}\right)^{\alpha}\left(\bar{\delta}_{H T} Y^{P}-z_{0}\right)^{1-\alpha} .
$$

By deriving the above formula, it is straightforward to show that $\tilde{u}_{e}^{P}\left(\bar{\delta}_{H T}\right)$ strictly decreases with $\bar{\delta}_{H T}$. The size of the low-income residential area is given by the same equation as in the second regime. Using the same rationale as before (added to the fact that because utility decreases, lot sizes decrease even more), the size of the low-income area also strictly decreases in the third regime.

\section{Proof of Proposition 4}

Consider the same three regimes as in the proof of Proposition 3. In the first regime, the CHT constraint is ineffective, so both the mean and the range of solvency levels remain constant.

In the second regime, utility remains constant. When $\bar{\delta}_{H T}$ increases, $\tilde{z}\left(r, \tilde{u}_{e}^{P}\right)$ strictly increases for all constrained households and remains constant for unconstrained households (from (15)). Therefore, the mean solvency level increases while the range decreases.

In the last regime, all households are constrained. Again from (15), the solvency level is the same for all households and equal to $\bar{\delta}_{H T}$. The mean is thus also $\bar{\delta}_{H T}$ while the range is null. 


\section{Appendix B - Figures}

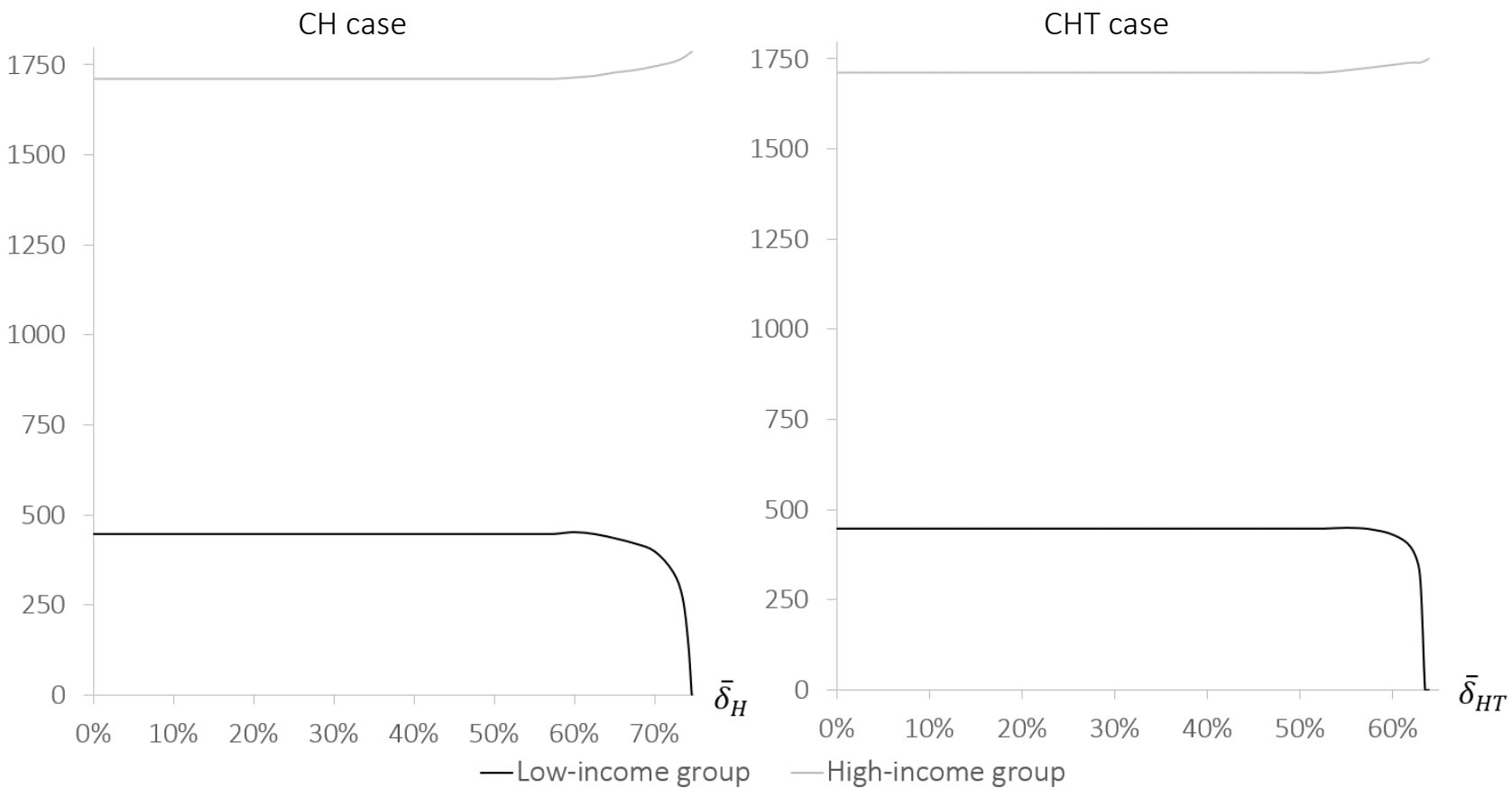

FIGURE A.1: INFLUENCE OF CH AND CHT POLICIES ON HOUSEHOLD UTILITY (PARIS REGION) 